Florida International University FIU Digital Commons

$11-23-2009$

\title{
Does Hope Matter? The Influence of Dispositional Hope on Persistence in a Developmental Writing Course
}

Stephen S. Madison

Florida International University, mrmadisonx@gmail.com

DOI: $10.25148 /$ etd.FI09120821

Follow this and additional works at: https://digitalcommons.fiu.edu/etd

\section{Recommended Citation}

Madison, Stephen S., "Does Hope Matter? The Influence of Dispositional Hope on Persistence in a Developmental Writing Course" (2009). FIU Electronic Theses and Dissertations. 130.

https://digitalcommons.fiu.edu/etd/130 


\title{
FLORIDA INTERNATIONAL UNIVERSITY \\ Miami, Florida
}

\section{DOES HOPE MATTER? THE INFLUENCE OF DISPOSITIONAL HOPE ON}

PERSISTENCE IN A DEVELOPMENTAL WRITING COURSE

\author{
A dissertation submitted in partial fulfillment of the \\ requirements for the degree of \\ DOCTOR OF EDUCATION \\ in \\ HIGHER EDUCATION
}

by

Stephen Sean Madison 
To: Interim Dean Marie McDemmond

College of Education

This dissertation, written by Stephen Sean Madison, and entitled Does Hope Matter? The Influence on Dispositional Hope on Persistence in a Developmental Writing Course, having been approved in respect to style and intellectual content, is referred to you for judgment.

We have read this dissertation and recommend that it be approved.

$\begin{array}{r}\hline \text { Jean Rahier } \\ \hline \text { Janice Sandiford } \\ \hline \text { Joan Wynne } \\ \hline \text { Glenda Droogsma Musoba, Major Professor }\end{array}$

Date of Defense: November 23, 2009

The dissertation of Stephen Sean Madison is approved.

Interim Dean Marie McDemmond

College of Education

Dean George Walker

University Graduate School

Florida International University, 2009 


\section{DEDICATION}

This dissertation is dedicated to my grandmother, Hazel Magee (aka "Oma”). I may have travelled a different path if it were not for her intervention, love, and support. I appreciate the sacrifices that my grandmother made in her life so that my life might have meaning.

I dedicate this work to my mother, Chancesllor Magee-Madison, who carefully fostered my intellectual curiosity, spiritual foundation, and love of learning during my early years. I remember your prayers, and I remember God's answers.

Lastly, I dedicate this work to my deceased father, Anton Joseph Madison. I was only 4 years-old when my father departed this life, yet pictures remind me of a man who wanted only the best for his only child. If he still has the capacity to emote (wherever he is), I can only hope that he is proud of his son. 


\section{ACKNOWLEDGEMENTS}

First, I acknowledge God, who has taught me, by His Spirit, that challenges produce persistence; persistence builds character, and character informs the kind of hope that has never failed me. Hence, I am a prisoner of hope, and my future is brighter because God keeps me.

I am indebted to my committee members - Dr. Janice Sandiford, Dr. Joan Wynne, and Dr. Jean Rahier - for their invaluable guidance and unwavering support throughout this doctoral process. I admire not only their scholarship but also their contributions to a new generation of thinkers (and practitioners) in higher education. I am especially grateful to my major professor, Dr. Glenda Musoba, who coached and encouraged me along this journey. Without question, she helped me to demystify the process, making the attainment of a doctoral degree achievable.

I appreciate my community of mentors - trusted friends, confidants, seasoned professionals, and teachers - who have lent their support in my personal and professional endeavors. They include: Dr. Alexandria J. Holloway, Apostle Carlos L. Malone, Sr., Dr. Vernon Smith, Dr. Castell V. Bryant, Mr. Herb Robinson and the late Dr. Leslie Roberts.

I am also indebted to countless individuals who have supported and encouraged me over the years. I thank the leadership and my colleagues at Miami Dade College. While I am hesitant to name individuals for fear of inadvertently omitting someone, I would be remiss if I did not acknowledge the assistance of the following individuals: Dr. Joanne Bashford, Dr. Ernesto Valdes, Ms. Rita Fernandez, and Ms. Merlene Purkiss. These individuals were instrumental in supporting me throughout various phases of my research. 


\title{
ABSTRACT OF THE DISSERTATION \\ DOES HOPE MATTER? THE INFLUENCE OF DISPOSITIONAL HOPE ON PERSISTENCE IN A DEVELOPMENTAL WRITING COURSE
}

\author{
by
}

\section{Stephen Sean Madison}

Florida International University, 2009

Professor Glenda Droogsma Musoba, Major Professor

The purpose of this study was to determine hope's unique role, if any, in predicting persistence in a developmental writing course. Perceived academic selfefficacy was also included as a variable of interest for comparison because self-efficacy has been more widely studied than hope in terms of its non-cognitive role in predicting academic outcomes. A significant body of research indicates that self-efficacy influences academic motivation to persist and academic performance. Hope, however, is an emerging psychological construct in the study of non-cognitive factors that influence college outcomes and warrants further exploration in higher education. This study examined the predictive value of hope and self-efficacy on persistence in a developmental writing course.

The research sample was obtained from a community college in the southeastern United States. Participants were 238 students enrolled in developmental writing courses during their first year of college. Participants were given a questionnaire that included measures for perceived academic self-efficacy and hope. The self-efficacy scale asked participants to self-report on their beliefs about how they cope with different academic tasks in order to be successful. The hope scale asked students to self-report on their 
beliefs about their capability to initiate action towards a goal ("agency") and create a plan to attain these goals ("pathways").

This study utilized a correlational research design. A statistical association was estimated between hope and self-efficacy as well as the unique variance contributed by each on course persistence. Correlational analysis confirmed a significant relationship between hope and perceived academic self-efficacy, and a Fisher's z-transformation confirmed a stronger relationship between the agency component of hope and perceived academic self-efficacy than for the pathways component. A series of multinomial logistic regression analyses were conducted to assess if (a) perceived self-efficacy and hope predict course persistence, (b) hope independent of self-efficacy predicts course persistence, and (c) if including the interaction of perceived self-efficacy and hope predicts course persistence. It was found that hope was only significant independent of self-efficacy. Some implications for future research are drawn for those who lead and coordinate academic support initiatives in student and academic affairs. 


\section{TABLE OF CONTENTS}

CHAPTER

PAGE

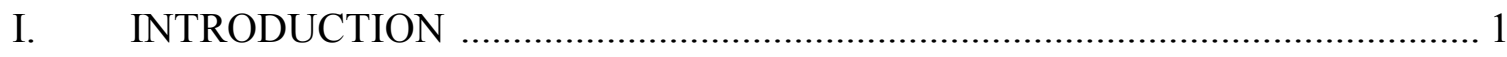

Purpose and Significance of the Study .......................................................... 4

Statement of the Problem............................................................................... 5

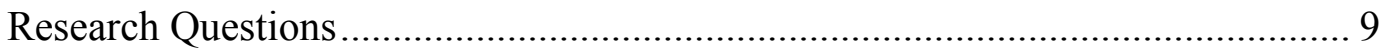

Overview of Relevant Retention/Persistence Theories.......................................... 9

Evolving Motivational Theories in Understanding Student Departure..................12

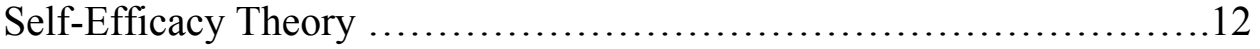

Positive Psychology and Hope Theory ............................. 14

Clarifying the Difference between Hope, Self-efficacy, and Other

Motivational Constructs .............................................. 15

Scope of the Study .................................................... 17

Definition of Key Terms ............................................... 18

Delimitations ......................................................... 20

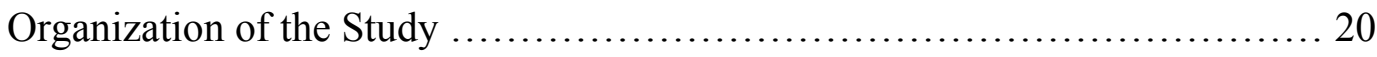

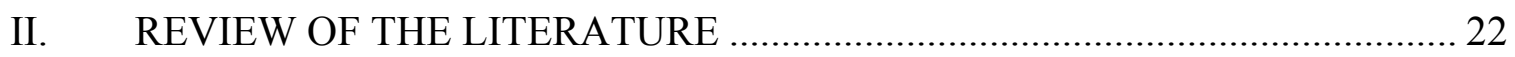

Non-Cognitive Influences on Academic Outcomes ............................................ 23

Self-Efficacy and Academic Outcomes ............................................................. 25

Self-Efficacy and Persistence .............................................................................. 29

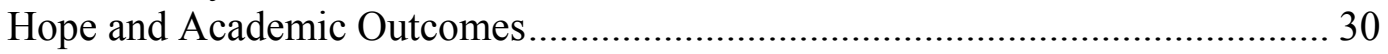

Hope and Persistence ....................................................... 32

Hope and Self-Efficacy as Co-Factors in Influencing Academic Outcomes......... 34

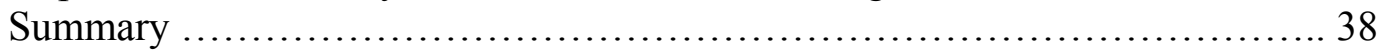

III. RESEARCH DESIGN AND METHODOLOGY ………................................. 40

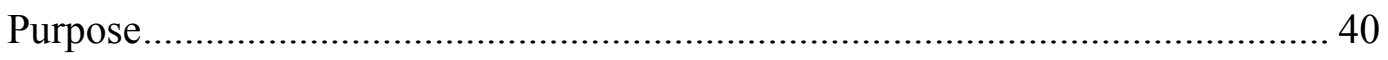

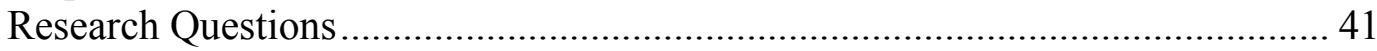

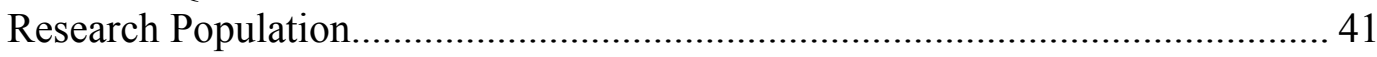

Participants and Sample Selection .................................................................... 42

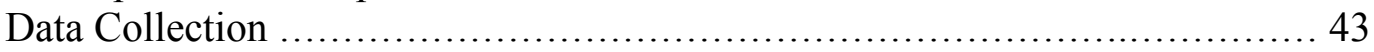

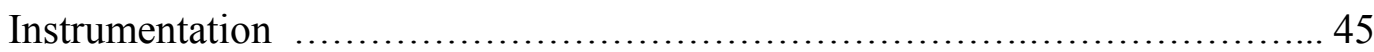

Perceived Academic Self-Efficacy Scale ............................ 45

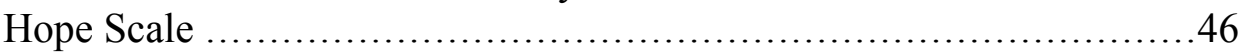

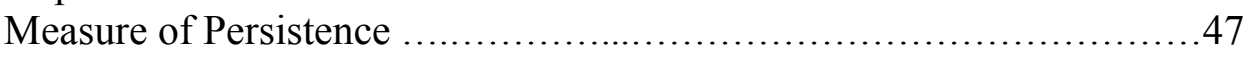

Data Analysis Procedures ....................................................... 48

Methodological Limitations.............................................. 52

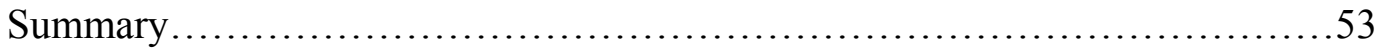

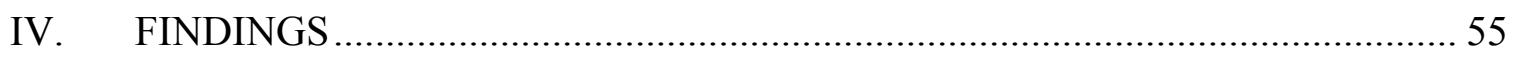

Descriptive Statistics for Independent, Non-Cognitive, and Dependent Variables 
Chi-Square Tests for Relationship between Non-Cognitive and Dependent

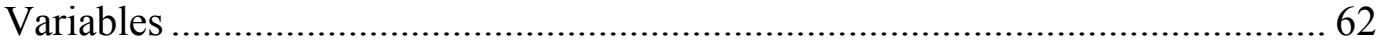

Analysis of Variance for Relationship between Age

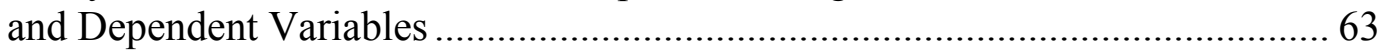

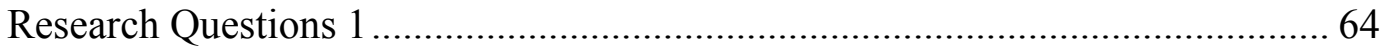

Research Questions 2 ..............................................64

Research Questions 3 ...............................................66

Research Questions 4 ...................................................68

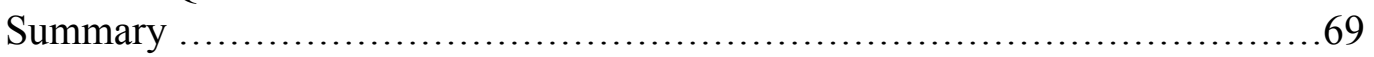

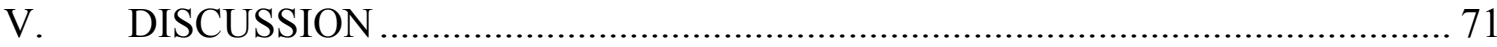

Discussion of Findings Based on Research Questions ................................... 72

Implications for Additional Research......................................... 77

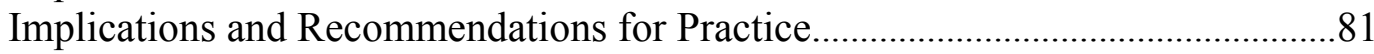

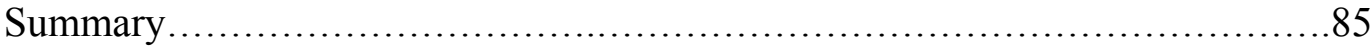

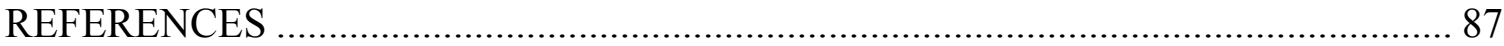

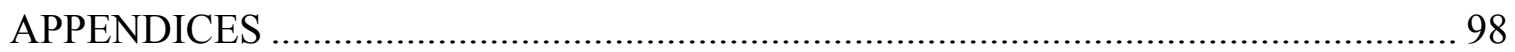

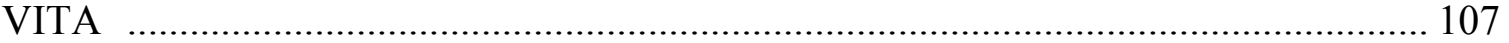




\section{LIST OF TABLES}

TABLE

PAGE

1. Variable Names and Descriptions.................................................... 50

2. Frequencies and Percentages on Enrollment Status...................................... 56

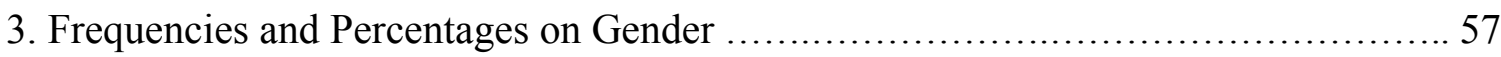

4. Frequencies and Percentages on Ethnicity/Race ….................................. 57

5. Frequencies and Percentages on Native Language .................................... 58

6. Frequencies and Percentages on Hours Worked While in College ...................... 58

7. Frequencies and Percentages on Total Family Income ….............................. 59

8. Frequencies and Percentages on Either Parent's Highest Education Level ........... 60

9. Means and Standard Deviations on Composite Hope and Perceived Academic Self-Efficacy Scores ..................................... 61

10. Frequencies and Percentages on Course Persistence................................... 62

11. Chi-Square Values on Demographic Categorical Variables

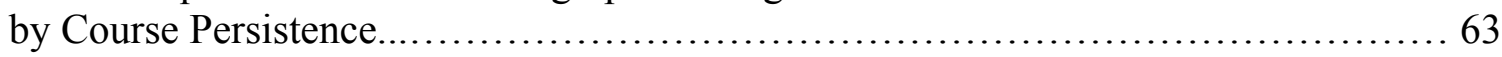

12. ANOVA on Age by Course Persistence ......................................... 63

13. Multinomial Logistic Regression with Self-Efficacy and Hope Predicting Course

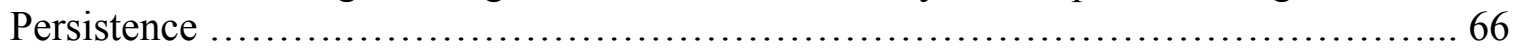

14. Multinomial Logistic Regression with Hope

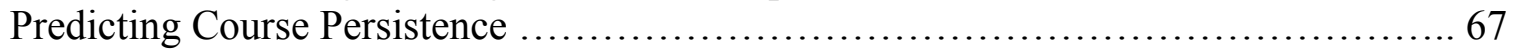

15. Multinomial Logistic Regression with Self-Efficacy

Predicting Course Persistence ................................................... 67

16. Multinomial Logistic Regression with Self-Efficacy, Hope, and the Interaction of Self-Efficacy and Hope Predicting Course Persistence ............................... 68 


\section{CHAPTER I}

\section{INTRODUCTION}

In this new age of accountability in American higher education, student retention is a critical issue. Amidst changing student markets, rising tuition costs, and reduced funding for higher education in some states, stakeholders in higher education are grappling with strategies - if not interventions - to sustain the gains some institutions have reported in college access and college completion in recent years. According to U.S. Department of Education (2006), "too few Americans prepare for, participate in, and complete higher education - especially those in underserved and nontraditional groups who make up an ever-greater proportion of the population" (p. 8). A report released by the College Board states that tuition and fees at 4-year public colleges have increased by $31 \%$ in the last 5 years, after adjustment for inflation (Baum, Brodigan, \& Ma, 2007). The report also found that tuition prices had increased at private colleges and at 2-year colleges (Baum et al., 2007). This shortcoming in access and retention, as both reports suggest, is a result of "the complex interplay of inadequate preparation...and persistent financial barriers" (U.S. Department of Education, 2006, p. 8) that further exacerbate the issue. Moreover, in some academic contexts, this interplay has multiple implications.

At many public 2-year or community colleges, an open door admission policy has provided an opportunity for students to attain a college education, and, in many states, this attainment is at a fraction of the cost that it would be to attend a private college or 4year public university. Yet, many of these 2-year admits need pre-college coursework as evidenced by student performance on college entrance and placement exams. Nationally, in fall 2000, about $30 \%$ of all students entering American postsecondary institutions 
required some form of remediation or "developmental education" (National Center for Education Statistics [NCES], 2004b). About 43\% of all students entering American public 2-year colleges required some form of remediation, usually in mathematics, writing, or reading (NCES, 2004a). Fifty-eight percent of students who take no remedial education courses earn a Bachelor's degree within 8 years, but only $17 \%$ of students who enroll in a remedial reading course receive a Bachelor of Arts or Bachelor of Science degree within the same period (NCES, 2004a).

For some higher education pundits, this need to remediate costs the nation billions of dollars and absorbs funding from other priority areas. For others, such as Alexander W. Astin (2000), higher education scholar and founding director of the Higher Education Research Institute at University of California, Los Angeles, this need to remediate these students is "the most important educational problem in America today" (p.130) given the confounding influence that academic underpreparedness has on attrition at any educational level. Nevertheless, these institutions usually serve a high percentage of nontraditional student populations who are "at-risk" when compared to their traditional counterparts. Consequently, many of these students start their education in developmental programs (i.e., remedial or basic skills programs) because of their lack of academic readiness for college.

What is alarming, however, is that years of research consistently support that the strongest predictor of retention in higher education is based on academic preparation and skills (American College Testing Program [ACT], 1998; Boldt, 1986; Mouw \& Khanna, 1993), yet community colleges are purposed to provide an opportunity for these students 
to attain critical postsecondary credentials (e.g., Associate's degree) to improve their quality of life.

Indeed, these findings suggest that students who participate in these programs are not likely to persist in comparison to those students who did not require developmental education or those students who matriculated at 4-year colleges and universities. In other words, the prospect of students completing just an associate degree program or even a certificate program at the community college is ominous, and this is a grave concern for many community college faculty members and administrators.

As mentioned earlier, the strongest predictor of retention in higher education is based on academic preparation and skills (ACT, 1997; Boldt, 1986; Mouw \& Khanna, 1993), and many retention programs are designed to address this lack in academic preparation through developmental education in the form of such initiatives as academic support centers and non-credit courses. Many of these retention programs also ground their strategies based on some of the early models of retention that focus on student engagement with the college or university as a key factor in the student departure decision. Tinto (2006), however, suggests that because of the complex issue of retention, recent studies are exploring other factors not emphatically addressed in the early retention literature. Higbee, Arendale, and Lundell (2005) recommend that future studies in retention examine more affective barriers to student achievement that would include the use of multiple measures to assess, for example, student motivation, especially in developmental education. Certainly, this approach would de-emphasize the institution and focus on the assessed and developmental needs of some students. In fact, after controls have been established for academic preparation and skills, research may show 
that other factors - social and motivational - may positively influence retention and academic success (Kahn \& Nauta, 2001). Some of these motivational and social factors include the relationship between spirituality and college outcomes (Astin, 2004), coping strategies and persistence (Castles, 2004), and the positive relationship between selfbeliefs and persistence (Gloria, Robinson Kurpius, Hamilton, \& Wilson, 1999; Solberg, O'Brien, Villareal, Kenner, \& Davis, 1993). While there continues to be significant study in these areas, this study focuses on the interrelationship of two self-belief constructs self-efficacy, which has received a considerable amount of attention in the literature, and hope, a relatively new construct for exploration, which is receiving more attention within the context of higher education.

\section{Purpose and Significance of the Study}

Self-efficacy influences academic motivation to persist (Schunk \& Pajares, 2002). Self-efficacy beliefs are correlated with motivational constructs and with students' academic performance and achievement (Pajares, 2003). Hope, however, is an emerging psychological construct in the study of factors that influence college outcomes and warrants further exploration within the context of the student departure decision and academic performance. The purpose of this study was to determine hope's role, if any, in predicting persistence in a developmental writing course. Specifically, this study was designed to determine the relationship of these motivational constructs, primarily hope, on students who persist in developmental writing courses.

The outcomes and implications of this study are important for those who lead and coordinate academic support initiatives in student and academic affairs, in particular, and in developmental education and retention programs. When asked which internal issues 
were important to their institution, a national sample of community college presidents not only indicated that student retention was of greatest importance but also suggested that different strategies such as new pedagogies to meet changing student needs would be needed to positively impact these issues (Amey \& VanDerLinden, 2002). The outcomes and implications from this study may also inform institutional practice by expanding the culture of academic support to include more affective intervention strategies and by increasing retention among non-traditional students or students who are at-risk of failing in the first year of college enrollment.

\section{Statement of the Problem}

The largest proportion of student departure occurs during the first year of college (Terenzini \& Reason, 2005), and, for about $43 \%$ of students entering American higher education, the first year involves enrollment in a developmental education course (NCES, 2004a). Moreover, student departure in the first year or first term at a 2-year college has been understudied in comparison to 4-year institutions (Townsend, Donaldson, \& Wilson, 2004). Nora, Barlow, and Crisp (2005) analyzed persistence rates of 2,906 firsttime-in-college students entering in the fall 1997 at a public, commuter, doctoral-granting institution and found that $13.7 \%$ (approximately 398 students) enrolled a developmental English course. Accordingly, students who successfully completed developmental English in the first year and on the first attempt (39.7\%) appeared to be more likely to persist to graduation within 6 years. Of those students who successfully completed after a second attempt during the first-year, $17.6 \%$ were less likely than their first attempt counterparts to persist to graduation within 6 years. This finding about the role of writing is consistent with a recent National Bureau of Economic Research study on remediation 
that found that students who took developmental English were $17 \%$ more likely to graduate in 4 years and $19 \%$ less likely to transfer out compared with those who did not take the class but needed the course (Bettinger \& Long, 2005). Implications from these findings about success in developmental writing may have repercussions even beyond the higher education institution.

In many facets of society, individuals are required to demonstrate writing competency not only in colleges but also in various industries (White \& Thomas, 1981). Gaps in these writing skills, however, may negatively impact an individual's socioeconomic progress or attainment of the American dream, which for many means home ownership, educational attainment, and employment. In fact, the National Commission on Writing for America's Families, Schools and Colleges (2004) surveyed 120 chief executive officers from some of the United States' leading corporations, including manufacturing, transportation, and utilities, and found that people who cannot write and communicate clearly are less likely to be hired and to be retained long enough to be considered for promotion. Individuals who cannot write in the United States can clearly find employment, but the opportunities for salaried employment are limited for employees unable to communicate clearly. Moreover, it is interesting to note that those who are most likely at-risk of not attaining these skills are those who are poor, minorities, limited in English proficiency, or learning English to secure low-skill, low-wage, hourly employment. In order to support those at-risk who aspire to attain writing skills, community colleges, at times, must address multiple levels of readiness that may require placement in two or three courses in the first (or even second) year prior to enrolling in college-level English. 
A number of studies also support the importance of not only academic performance but also non-cognitive dimensions measured in the first year and their impact on academic outcomes such as graduation and transfer to a 4-year college or university. For example, Tracey and Sedlacek (1987) found that non-cognitive factors, such as realistic self-appraisal, measured in the first semester were more predictive of subsequent persistence than first semester grades in African American students. In a later study, Allen (1999) found similar results based on a different non-cognitive factor (i.e., desire to finish) where minority students with high levels of this factor, as measured by Noel and Levitz's College Student Inventory, tended to persist to their second year.

Patrick Terenzini (2006) calls for researchers to expand their understanding of the range of influences on persistence through a systematic process that includes deeper analysis of principles that underlie educational practices. As indicated in a number of studies on the importance of the first-year, these principles may be psychological, and this study took into consideration two psychological or motivational factors: hope and self-efficacy. An understanding of how these two factors correlate with academic performance for students who begin in developmental education provides an opportunity for researchers to test new and build upon previously investigated explanatory factors that impact the student departure decision, especially in the first year.

For example, some studies have cited the discouragement and disengagement students may experience as participants in developmental education programs that may, in turn, negatively impact college or course completion (Richardson, Okun, \& Fisk, 1983). Another way of mediating an understanding of this discouragement is through its positive counterpart, hope, which has been studied primarily in the health field among the 
terminally ill. However, only a couple studies have explored the relationship between hope and persistence in the area of higher education (Snyder, Rand, \& Sigmon, 2002; Snyder \& Lopez, 2007). Based on these studies, further research is warranted with emphasis on how hope interacts with other more highly studied dispositional variables, such as self-efficacy, in higher education.

Although there is a body of research on motivational theory (e.g., self-efficacy) and its effect on college outcomes, such as persistence behavior, a lack of this research exists on community college students (Nakajima, 2008), especially with emphasis on those students who enroll in developmental education courses. In fact, most of the retention studies collect data on residential baccalaureate institutions, and findings from these institutions may not be generalizable to community colleges, which are generally 2year and commuter institutions with less academically prepared students. In recent decades, researchers have been more engaged in issues related to persistence in developmental education (Higbee, Arendale, \& Lundell, 2005). To positively influence persistence for students enrolled in developmental coursework, it is important to consider non-cognitive factors that might influence student success and implement multiple measures to explore motivational factors that affect student success (Higbee et al., 2005).

A few studies have been conducted on students in developmental mathematics and the relationship between self-efficacy and mathematics (Bassarear, 1991; Hall \& Ponton, 2005; Rushing, 1996), and interest in this area is growing. A few studies have been conducted in reading and the relationship between reading skills, self-efficacy, and self-motivation (Stone, 1994), and interest, too, in this area is growing. Nevertheless, there are limited studies on the relationship between writing and self-efficacy in 
developmental education at the community college (Pajares, 2003; Wachholz \&

Etheridge, 1996), and this study contributes to the research in the aforementioned area.

\section{Research Questions}

The research questions addressed by this study are as follows:

1. Are hope and self-efficacy distinct for students enrolled in a developmental writing course?

2. After controlling (if significant) for more traditional, research-supported factors that influence student retention at the community college, to what extent do selfefficacy and hope predict course completion in a developmental education course during the first year of college?

3. Does hope account for a significant amount of unique variance independent of self-efficacy?

4. What is the interaction of self-efficacy and hope in predicting completion of a developmental writing course during the first year of college?

Overview of Relevant Retention/Persistence Theories

Since the early retention studies of the 1930s, scholars have been engaged in the study of college student departure from a number of perspectives (Berger \& Lyon, 2005; Braxton 2000). Although most of the research, at least within the last 3 decades, has roots in social theory, the interplay between psychological and sociological approaches to explain student departure from college has influenced the production of a substantial and expanding body of literature (Pascarella \& Terenzini, 2005; Tierney, 1992; Tinto, 1993). Based on Durkheim's (1897/1950) suicide model, Spady (1970) was the first to propose a widely recognized model for college student dropout. From a social 
perspective, Durkheim believed that social forces such as forms of government, financial conditions, degree of integration with society, heredity, race, and individual psychopathic states (e.g., mental illness) influenced, if not explained, a decision about whether or not to commit suicide. Driven by similar and expanded sociological characteristics and processes, Spady's (1970) model indicated that five variables, such as academic potential, normative congruence, grade and performance, intellectual development, and friendship support, informed a decision to drop out. This model, however, did not take into consideration individual psychological characteristics that, too, might influence the decision to drop-out or how those social situations might lead an individual to the decision, perhaps by way of a psychocognitive process, to withdraw.

Driven primarily by a sociological foundation, Tinto $(1975,1993)$, probably one of the most well known researchers in college student departure, established a social and academic integration model for understanding the problem of student departure that extended Spady's (1970) work. Tinto also used Van Gennep's (1960) framework dealing with the rites of passage that involves the process of moving individuals and societies at designated times and, in particular, the process of moving from youth to adulthood (Braxton, 2000). Accordingly, Tinto's (1975) model proposes that factors such as personal goals, pre-college academic preparedness, socio-economic background, academic performance, and campus academic and social interaction drive a decision whether or not to depart from the institution. Within this model, persistence operates as a function of the match between an individual's motivation and academic ability and the institution's academic and social characteristics (Cabrera, Castaneda, Nora, \& Hengstler, 1992). Tinto's model, nonetheless, introduces some psychological pre-college 
dispositions (e.g., motivation) to understand the quality of a student's interaction with the institution. The interaction between a student's motivation, drive, and academic ability and institutional features help inform the fit between the student and the institution.

In the 1980s, more research grounded in psychological and sociopsychological theories began to develop. Early psychological approaches involved Bentler and Speckart's (1979) adaptation of Fishbein and Ajzen's (1974) theory that behavior is not only determined by an individual's intention to perform or not perform the behavior but is also predicted by a combination of attitudes, intentions, and past behaviors.

Accordingly, this approach provides a foundation for understanding student departure in Bean's (1983) Model of Student Departure, a psychological processes model.

An adaptation of an organizational turnover model (Price, 1977), Bean's (1983) model evolved into one where the overall structure was based on a psychological model that identified a link between students' attitudes and behaviors, linking the student departure decision (a distinct behavior) with similar past behavior, normative values, attitudes, and intentions. Although based on psychological processes, the model was similar to Tinto's in that it was complex and longitudinal. However, the model differed from Tinto's original model by including environmental variables that were external to the institution (Cabrera, Nora, \& Castenada, 1993). Bean and Eaton (2000) further developed a psychological model that integrated four psychological theories: attitudebehavior theory, coping behavior theory, self-efficacy theory, and attribution theory. Of the four theories, self-efficacy was important for the purposes of this study. Self-efficacy is an individual's perception of his/her capability to deal with specific tasks or situations. 
Within the context of Bean and Eaton's model, these self-perceptions may serve as indicators or predictors of persistence.

\section{Evolving Motivational Theories in Understanding Student Departure}

In the past decade, motivational theories drawn from many psychological studies have informed explanatory models of college outcomes, including the student departure decision. Moreover, researchers have been rethinking the various approaches to student success and persistence in developmental education programs (Damashek, 1999; Stratton, 1998), and further study of dispositional constructs such as spirituality (Astin, 2004) and hope (Snyder et al., 2002) has been developed to contribute to the understanding of the student departure decision. This kind of research is important in understanding the success of students who enroll in developmental education programs, especially when some studies report that many students are unsuccessful in or do not complete these programs (Adelman, 2006).

\section{Self-Efficacy Theory}

Self-efficacy theory is an extension of Bandura's (1977) social cognitive theory, which explains behavior, such as learning, and its interdependent relationship with environmental, cognitive, and emotional factors. More specifically, self-efficacy deals with an individual's belief that she or he is capable of learning and/or performing specific tasks. An individual who demonstrates high levels of self-efficacy is likely to accept a challenge and to be intrinsically motivated in various environments. In contrast to a reactive individual whose capacity to perform a task may be influenced by environmental forces, the self-efficacious individual may be perceived as proactive and capable of moderating self-beliefs to control thoughts, actions, or emotions that might impede 
successful performance (Pajares, 2003). In an academic setting, according to Pajares (1996), these self-beliefs about a learner's ability to perform tasks related to academic outcomes can influence student success in both positive and negative ways. For example, some researchers even suggest that high levels of self-efficacy in a difficult course is critical to student success given the varying levels of anxiety that may also be present (Baldwin, Ebert-May, \& Burns, 1999; Bandura, 1997).

Self-efficacy is an important mediator between knowledge, attitudes, and performance and can be developed (Bandura, 1997). In his theory, Bandura (1986) identifies four sources that can inform an individual's efficaciousness. The most influential source is enactive or performance attainment that is based on an individual's prior experiences with success or failure. This individual tends to demonstrate a high level of self-efficacy when she or he can associate the task with other or previous situations where she or he has been efficacious. Another source is an individual's vicarious experience where beliefs about an individual's capability to perform a task are influenced by observing others, who have perceived similar capabilities, perform the same or associated tasks. Social or verbal persuasion can also inform efficacious behavior. This individual tends to be motivated by someone in whom the individual has confidence. Bandura warns that this influence can be detrimental if realistic boundaries for success on the task have not been identified. The last source deals with an individual's psychological state that can heighten an individual's perception of her or his self-efficacy in various situations. Depending on the case, this psychological influence can negatively or positively impact performance. 
Additional study of self-efficacy beliefs informs educational practice and the predictability of behavior that will lead to positive academic outcomes. Findings from these studies may also support holistic student growth and maximize student learning that can influence both retention and achievement in college settings.

Positive Psychology and Hope Theory

Positive psychology provides the theoretical foundation for understanding selfefficacy and hope. In January 1998, Martin Seligman, coined the phrase "positive psychology," which described a movement among psychologists whose research emphasized the relative importance that positive psychological strengths and capabilities such as hope and self-efficacy can have on human functioning (Wallis, 2005). Based partly on the assumption that the totality of the human experience has been overshadowed by psychological studies that focus on disorder, disease, and distress (Seligman \& Csikszentmihalyi, 2000), Gable and Haidt (2005) define positive psychology as "the study of the human condition and processes that contribute to the flourishing or optimal functioning of people, groups and institutions" (p. 104).

Contributing to this positive psychological movement, Snyder (2000) advances hope as a human strength that can be both meaningful and measurable in understanding human functioning. Snyder (2000) provides a comprehensive survey on hope as a psychological construct which includes its development as a theory. For Snyder (2000), hope is defined as "a cognitive set that is based on a reciprocally-derived sense of successful agency (goal-directed determination) and pathways (planning to meet goals)" (p. 9). Pathways thinking, then, refers to one's capability to create routes to goals. Agency thinking refers to one's capability to persist until those goals are attained. The 
onset of barriers in this interplay of pathways thinking and agency thinking complicates this process whereby one either can be stopped or create alternate or multiple paths to goal attainment (Irving, Snyder, \& Crowson, 1998; Snyder, 1994). Linking goal orientations and hope, Roedel, Schraw, and Plake (1994) found a correlation between pathways and learning goals.

Clarifying the Difference Between Hope, Self-Efficacy, and Other Motivational

\section{Constructs}

Studies have stressed the importance of distinguishing between hope and related constructs such as optimism and self-efficacy when examining predictive value in varying contexts (Peterson, 2000; Shorey, Snyder, Rand, Hockemeyer, \& Feldman, 2002; Tennen, Affleck, \& Tennen, 2002). In general, Scheier and Carver (1987) indicate that optimism is to be regarded as a cognitive variable as opposed to non-cognitive, a classification that hope has because of its emphasis as an emotion or dispositional construct with cognitive components (Staats, 1989). Optimism is a general expectation that good outcomes will occur (Scheier \& Carver, 1987), but the measurement, as indicated by Peterson, Gerhardt, and Rode (2006), does not address the means or pathways by which these desired outcomes will occur. Hope contains both pathways and goals.

As for the difference between self-efficacy and hope, Snyder, Rand, and Sigmon (2002) emphasize the difference between the "words can and will, with the former referring to the capacity to act and the latter reflecting the intention to act-with intention being more willful" (p. 58). As mentioned earlier, self-efficacy deals with an individual's belief that she or he is capable of learning and/or performing specific tasks, and Peterson, 
Gerhardt and Rode (2006) indicate that this capability is akin to the agency (willpower) component of hope, but it does not incorporate hope's pathways component.

In one study, Magaletta and Oliver (1999) found hope to be a significant predictor of outcomes such as subjective well-being and other mental health outcomes after controlling for variance as a result of optimism and self-efficacy. Magaletta and Oliver (1999) examined the relationship between conceptually related constructs: hope, selfefficacy, optimism, and well-being. Their purpose was two-fold: to identify "underlying operationalizations when the unit of analysis selected was individual items comprising each measure" (p. 549), to determine whether the Hope Scale significantly and uniquely contributed to well-being at higher levels than self-efficacy or optimism, and to determine whether each of the components of the Hope Scale and the Will and Ways subscales contributed, independently, to predicting general well-being.

Magaletta and Oliver (1999) selected 204 students from psychology classes at a midsize Catholic university in the Midwest and asked them to respond to four measures: (a) the Hope Scale, which was designed to measure hope and assess both will and ways; (b) the Self-Efficacy Scale (SES), which was designed to measure perceived selfefficacy, or one's general expectations regarding one's ability to perform behaviors; (c) the Life Orientation Test, which was designed to measure dispositional optimism, or the generalized expectancy that one will experience positive outcomes in life; and (d) the General Well-Being Questionnaire, which was designed as a general measure of positive mental and physical health.

Magalatta and Oliver (1999) conducted a factor analysis that suggested empirical parallels between self-efficacy and the Will sub-scale of the Hope Scale. Three 
hierarchical multiple regression analyses were conduced to examine the predictive power of the Hope Scale. The first analysis demonstrated that Hope had a unique predictive power in comparison to the other measures. The second analysis suggested that the Will sub-scale performs similarly to the Self-Efficacy Scale, but the Ways sub-scale was not a significant predictor of well-being. The third analysis demonstrated the unique power of Will sub-scale to predict well-being in accord with SES.

Magalatta and Oliver (1999) findings support that will, ways, self-efficacy, and optimism are related but not identical constructs. Consistent with findings in their study that distinguishes hope and optimism, Bryant and Cvengras (2004) note that hope is more related to general self-efficacy than optimism. In particular, hope focuses more on the attainment of specific goals (Bryant \& Cvengras, 2004), and this focus is akin to the taskspecificity of self-efficacy (Bandura, 1986). Yet, hope and self-efficacy, though related, are still different constructs. Snyder and his colleagues (2002) write that self-efficacy emphasizes a "person's perception about how [he or she] can perform ... in a given situational context, hope ... [on the other hand] emphasizes the person's self-referential belief that she or he will initiate (and continue) the requisite actions" (p. 262).

\section{Scope of the Study}

This study included those students who were enrolled in developmental writing courses at an urban community college in the southeastern United States. These students were placed in these courses based on pre-admission test scores as mandated by a state statue that address readiness for college assessment, placement, and instruction. Twohundred thirty-eight students participated in the study, and these participants were drawn from 16 developmental writing courses. 
During the second week of the 16-week course, students were given two brief surveys: (a) the Perceived Academic Self-efficacy Scale, an adaptation of Schwarzer and Jerusalem's (1995) general self-efficacy instrument that was modified for academic purposes by Hudson (2007) and measures a student's beliefs about how she or he can cope with different academic tasks in order to be successful throughout an academic task and (b) the Adult Hope Scale (AHS) that measures Snyder's cognitive model of hope (Feldman \& Snyder, 2000; Snyder, 1994; Snyder, Harris et al, 1991). At the end of the 16-week course, students' grades, including withdrawal information, were collected and compared with survey scores using a multinomial regression design. Demographic data were collected via a brief student questionnaire and the college's institutional research office.

\section{Definition of Key Terms}

A multitude of terms abound in the study of retention and persistence, and there is, at times, inconsistent agreement on the conceptualization of terms (Berger \& Lyon, 2005). This section provides working definitions for key terms related to this study.

Academic success. Success criteria in developmental education courses are indicated by performance levels of mastery learning where $\mathrm{S}=$ Satisfactory, $\mathrm{P}=\mathrm{Progress}$, and $U=$ Unsatisfactory. These grades are used to evaluate student performance at the completion of the course.

Developmental education. A number of names are used to refer to developmental education, including basic skills and compensatory and remedial education. While several definitions exist, this study used a working definition of developmental education as postsecondary courses in reading, writing, or mathematics for college-level students 
lacking those skills necessary to perform college-level work at the level required by the institution (Parsad \& Lewis, 2003). These skills and knowledge are not evident during pre-admission assessment processes and may not have been acquired in previous secondary education. The institution, however, expects a certain level of mastery of these skills and knowledge before a student begins college coursework. Coursework taken at the developmental level does not apply toward credits earned for graduation.

Hope. This study uses Snyder's (2000) definition of hope, which is a goaldirected cognitive process that contains two components: pathways and agency. Pathways refer to the method an individual uses to perceive routes or pathways to the desired goal, and agency refers to the mental fortitude a person draws on to use those pathways. Lopez and her colleagues (2004) explain it as Individuals' perceptions of their capacities to (a) clearly conceptualize goals; (b) develop the specific strategies to reach those goals (pathways thinking); and (c) initiate and sustain the motivation for using those strategies (agency thinking). The pathways and agency components are both necessary, but neither by itself is sufficient to sustain successful goal pursuit. As such, pathways and agency thoughts are additive, reciprocal, and positively related, but they are not synonymous. (p. 388)

Perceived academic self-efficacy. According to Bandura (1993), perceived selfefficacy refers to an individual's perception of her or his ability to organize and execute actions required for specific types of performance. Accordingly, perceived academic selfefficacy refers to an individual's judgment to complete academic tasks (Zimmerman, 1995). Within an academic context, students who have a strong sense of efficacy are 
more likely to be self-motivated and put forth the necessary effort to meet a commitment or goal such as course completion. Students with low self-efficacy, however, believe that they cannot be successful and avoid challenging tasks, which may, in turn, manifest as failure to complete academic tasks (Bandura, 1994/1998). Chapter 3 describes how perceived academic self-efficacy was measured in this study.

Persistence. This term is used interchangeably with "retention", which refers to the ability an institution has to retain a student from admission to some later point, often graduation (Berger \& Lyon, 2005). Persistence, however, is a motivational construct that refers to an individual's desire or action to begin and complete a course (Berger \& Lyon, 2005). In this study because of the high within course drop out rate among developmental students, persistence was operationalized as course completion.

\section{Delimitations}

The study was delimited to those first-year students who were enrolled in a developmental education writing course at a community college in the Southeastern part of the United States. The researcher also introduced as co-variates those variables that have been previously investigated in correlational studies where positive relationships have been established. These co-variates were not exhaustive and served as indirect variables that could affect the relationship between persistence, as defined for this study, and the primary variables of interest, which were hope and self-efficacy.

Organization of the Study

This dissertation is organized into five chapters. Chapter 1 provides an overview of the extent of the problem of persistence for students who are enrolled in developmental education coursework and establishes a rationale for examining the role that self-efficacy 
and hope, as non-cognitive and motivation constructs, might play in influencing persistent behavior in these students. Relevant retention and motivation theories are articulated to provide a framework of meaning that guided the study. Accordingly, relevant terms are also defined and clarified. Chapter 2 provides prior research on selfefficacy and hope as non-cognitive variables and their predictive power to influence academic outcomes with emphasis on persistence, as it is defined in this study. The predictive value of both self-efficacy and hope are reviewed independent of each other and, where appropriate, in interaction with each other. Chapter 3 details the research method that used in this study. The research site, procedures, and statistical measures are described. Chapter 4 presents the results and details the statistical treatments used to examine each research question. Chapter 5 follows with a discussion of research findings with implications for additional research and for practice in developmental education programs at community colleges. 


\section{CHAPTER II}

\section{REVIEW OF THE LITERATURE}

Much of the empirical research that deals with retention supports the predictive role that academic factors, such as prior academic achievement, play in the college student's departure decision on multiple levels. Recent studies, however, recognize the role that non-cognitive factors play in this decision as well. In this study, the researcher examines the relationship of two non-cognitive factors, self-efficacy and hope. A significant amount of research exists on the former within the context of education (Nietfeld \& Enders, 2003; Pintrich \& Schunk, 1995). The latter, however, has received little attention, but there is growing interest in this construct and its plausible contributions to new trends in retention studies.

For academic and student affairs professionals, this kind of research has positive implications in terms of program development to support students' transition through college, but most of this research, however, does not lend itself to generalizability (Bailey \& Alfonso, 2005) because of its focus on single institutions, 4-year institutions, residential institutions, and the traditional college student who is White and affluent (Braxton, Hirschy, \& McClendon, 2004; Pascarella \& Terenzini, 2005). Additional studies are needed using community college student populations with special emphasis on those students who enter higher education without the requisite basic skills to be successful at the college level (Ley \& Young, 1998).

The review of literature is divided into six sections relevant to the questions of this study and begins with a brief examination of expanding research related to noncognitive factors that influence the student departure decision. In the four sections that 
follow, a review of the literature on specific factors, namely hope and self-efficacy, ensues: (a) self-efficacy and its influence on academic outcomes, (b) self-efficacy and its influence on persistence, (c) hope and its influence on academic outcomes, and (d) hope and its influence on persistence. The last section highlights those studies where hope and self-efficacy have been measured together to explore not only the predictive value of each construct - sometimes along with other motivation constructs - but also the unique interrelationship, if any, of the two constructs. This chapter concludes with a summary of the review of literature.

\section{Non-Cognitive Influences on Academic Outcomes}

Researchers have demonstrated that previous academic performance is a good predictor of achievement in various academic settings, but it is not the only predictor that should be considered or isolated in understanding academic achievement and other academic outcomes in higher education. Based on findings in accumulating research and established theory, motivational factors are also predictive of behaviors related to academic outcomes such as persistence and grade performance. Robbins et al. (2004) meta-analyzed 109 studies to examine the relationship between psychosocial and study skills factors and college outcomes, specifically academic performance, as measured by grade point average, and persistence. After categorizing factors based on their motivational construct, Robbins and his colleagues (2004) found moderate relationships between retention and academic goals, academic self-efficacy, and academic-related skills ( $\rho=.340, .359$, and .366 , respectively). The best predictors for GPA were academic self-efficacy and achievement motivation ( $\rho=.496$ and .303 , respectively). After controlling for socio-economic status, high school GPA, and ACT/SAT scores, 
regression analyses confirmed the incremental contributions of the psychosocial and study skills factors in predicting college outcomes.

Robbins and his colleagues (2004) noted that the studies were limited across educational and psychological domains. For example, the studies were limited to only those that examined full-time students enrolled in 4-year colleges and universities in the United States. Moreover, none of these studies included participants from at-risk populations akin to those found at community colleges. These at-risk populations tend to enroll more students who enroll part-time, are academically underprepared for college, and work full-time while enrolled.

In one community college study, however, Hawley and Harris (2005) investigated factors, including non-cognitive factors that positively or negatively impacted persistence on first-year students at a large community college in Maryland. In fall 2000, 2,120 students were contacted to complete the Cooperative Institutional Research Program Freshman Survey. Of those who were contacted, 362 completed the survey, but only 133 students had usable social security numbers. Hence, Hawley and Harris (2005) used a respondent sample of 133 students for this study.

Hawley and Harris (2005) used factor and discriminant function analyses, and findings were consistent with a number of studies that support the positive influence of student social and academic engagement on student retention. Motivation to persist to a 4-year degree and GPA were strong predictors of persistence. The highest predictor of dropout was the amount of developmental or remedial education a student had to complete before taking college-level coursework, but no discussion ensues on the role that motivation played for these students. While Hawley and Harris' research sample 
selection is limited based on complications in data collection, it does provide implications that non-cognitive variables play a role worthy of additional investigation with a larger sample drawn from community college students who are enrolled in developmental education coursework.

Indeed, further research is needed on the predictive value of non-cognitive variables such as self-efficacy and hope in students who are not only enrolled in community colleges but also in the developmental education program. Traditionally, these students are perceived as "not successful" or "underprepared" for college-level work, and additional research to examine the impact of non-cognitive variables, especially those related to motivation, on their success in developmental education is important (Pintrich \& DeGroot, 1990; Ray \& Murdock, 2003).

\section{Self-Efficacy and Academic Outcomes}

One of the strongest non-cognitive constructs in predicting academic outcomes is self-efficacy, and research on self-efficacy and academic outcomes has received considerable attention in a number of areas, including college major and career choices and instructional practice (Pajares, 2003). For example, in one of only a few studies that focus on academically underprepared students at the start of college, Peterson and del Mas (1996) found that high levels of career-decision-making self-efficacy positively impacted students' decisions to persist in higher education. In studies related to academic performance and achievement, positive influences of self-efficacy have been found in academic disciplines such as statistics (Finney \& Schraw, 2003), mathematics (Pajares \& Miller, 1994), and writing (Meier, McCarthy, \& Schmeck, 1984; Shell, Murphy, \& Bruning, 1989; Zimmerman \& Bandura, 1994). Bandura $(1977,1993)$ has researched 
self-efficacy beliefs and found that self-efficacy beliefs affect college outcomes by increasing students' motivation and persistence to master challenging academic tasks and by fostering the efficient use of acquired knowledge and skills.

For example, Lopez, Lent, Brown, and Gore (1997) tested path models of academic interest and performance in a correlational study designed to expand research on mathematics self-efficacy by using Lent and his colleagues' (1994) framework. Accordingly, Lopez et al. surveyed 296 high school students: 151 geometry students and 145 advanced algebra students, using measures of mathematics ability, sources of mathematics self-efficacy, mathematics self-efficacy, and outcome expectations. The analysis yielded results that were consistent with causal models, in which self-efficacy and outcome expectations predict subject matter interest and self-efficacy partially mediates the effect of ability on course grades. These findings confirm research advanced by Bandura and Schunk (1981), which suggests that if a student feels confident in his or her ability to master an academic task, then that student is likely to demonstrate greater interest in the subject matter.

Multon, Brown, and Lent (1991) also confirmed a positive relationship between high academic performance and high self-efficacy in a meta-analysis based on selfefficacy studies executed from 1977 to 1988 . Accordingly, 39 studies with 41 different samples of subjects were meta-analyzed for either persistence or performance or for both. Findings suggest positive relationships between self-efficacy beliefs and academic outcomes, but more research is needed in the area of developmental education at the college level. Of the 39 studies examined, only 11 studies were conducted in a college 
setting, but most of these studies did not include developmental education or community college participants.

Gore's (2006) findings also suggest that academic self-efficacy beliefs can be used to predict academic performance and persistence in college students. Gore conducted a hierarchal linear regression analysis to evaluate the degree to which the ACT composite scores, College Self-Efficacy Inventory, and Academic Self-Confidence would predict college GPA. Participants were 629 first-year college students (335 males, 294 females) enrolled in a three-credit freshman orientation/transition course at a large public Midwestern university. Participants completed measures for achievement, college selfefficacy, and academic self-confidence during the first 2 weeks. Students' semester (noncumulative) GPAs and enrollment status were collected, and participants completed the College Self-Efficacy Inventory again during the last 2 weeks of the fall semester. Of the three scales, course self-efficacy was the most consistent predictor of college GPA. Gore emphasized that as a predictor it may be partially dependent upon the time of measurement, the domain measured, and the intended predictive outcome. This emphasis is consistent with some of the investigative features of this present study with regard to examining course completion as predicted by measures of self-efficacy and hope.

The extent to which implications can be drawn for developmental education or community college students is limited or unknown. Eighty-one percent of the participants in Gore's study (2006) reported high school GPAs of 2.5 or higher, and the mean ACT composite score of all the participants was 20.7, close to the national mean. These scores are not typical for community college students because community colleges enroll an academically diverse group of students, who have various reasons for going to college. 
Moreover, community colleges commonly have larger percentages of nontraditional and low-income students than 4-year colleges and universities, and some $95 \%$ of all community colleges are open-admission (Provasnik \& Planty, 2008). One view of this kind of access suggests that the least selective institutions are more likely than the more selective institutions to be challenged with lower retention rates and achievement, especially for students in developmental education.

As indicated earlier, self-efficacy has been thoroughly investigated in a number of academic contexts. The construct has also been examined in interaction with other motivational constructs and their effect on academic outcomes. For example, in a correlational study of the relationship of self-efficacy, self-concept, and academic performance, Choi (2005) focused on and examined the levels at which self-efficacy and self-concept better correspond with academic performance or grades. Participants in this study were 230 undergraduate students (129 female, 101 male) who were enrolled in four general education courses at a southeastern university. They completed three self-efficacy and two self-concept measures, and their grades were recorded at the completion of the course. Using correlation and multiple regression analysis, Choi found overall that the closer the level of specificity of self-efficacy and self-concept, the stronger the relationship between the two constructs, and both were significant predictors of term grades. While Choi's study was not conducted at a community college or with students enrolled in developmental education courses, research on commuter community colleges indicate that term grades, especially first semester grades, were significant, along with other factors, in predicting retention. 


\section{Self-Efficacy and Persistence}

An extensive body of research has shown that academic self-efficacy is positively associated with persistence (Lent, Brown, \& Larkin, 1984, 1986, 1987). In addition to finding a positive relationship between high academic performance and high self-efficacy (as mentioned earlier in the literature review), Multon et al. (1991) also confirmed a positive relationship between self-efficacy and persistence in a meta-analysis based on 18 self-efficacy studies executed from 1977 to 1988. This meta-analysis yielded an effect size of .34, where self-efficacy accounted for $12 \%$ of the students' academic persistence across various types of designs, student samples, and criterion variables, but studies that examine this relationship at the 2-year college are limited.

In a later study that includes students enrolled at 2-year colleges, Torres and Solberg (2001) examined the relationship between self-efficacy and persistence in Latino students. Participants were 179 students, consisting of 112 Latinas and 67 Latino males. This sample of 179 students consisted of 133 selected from two 2-year colleges and 46 randomly selected from two 4-year universities. Participants responded to measures of college stress, academic self-efficacy, social and faculty integration, persistence intentions, and stress. In the path analysis, Torres and Solberg found that college selfefficacy was associated with stronger persistence intentions, but whether college selfefficacy held any predictive value for actual persistence was not determined nor was the purpose of their research endeavor.

Both the meta-analysis (Multon et al., 1991) and Torres and Solberg's (2001)

study suggest that additional research on persistence is needed. Moreover, Multon et al. (1991) recommend that it is important to study this relationship in more challenging 
academic settings. Accordingly, in this current study, the researcher considered enrollment in development education courses a challenging academic context because the participants are less likely to graduate when compared to their counterparts who require no form of developmental education (Calcagno, Crosta, Bailey, \& Jenkins, 2006).

Calcagno et al. (2006) examined whether developmental education pathways had the same impact on program completion or graduation for older students as they did for younger students. Using event history modeling, Calcagno and his colleagues found that older students were more likely to graduate when compared to younger students after controlling for factors such as test scores and enrollment patterns. Therefore, research supports that persistence in these developmental education courses is essential to graduation, which may occur some 2 to 5 years later, and, based on a review of the literature, self-efficacy may be a mediating factor in supporting persistence as related to course completion for these students who are enrolled in developmental education (Nakajima, 2008; Zimmerman, 2000).

\section{Hope and Academic Outcomes}

Among correlation and prediction studies that examine the relationship between motivational factors and academic outcomes, hope theory research is relatively new in comparison to self-efficacy research. Based on the literature, self-efficacy generally has a stronger record of correlation to academic outcomes than hope. Research on dispositional hope and its relationship to academic outcomes, nevertheless, is promising, especially because more studies are finding relationships between high hope and better academic outcomes (Snyder, 2002). In fact, hope, as a "relatively stable personality disposition" (Lopez et al., 2004, p. 390), has been positively correlated in a number of studies related 
to health and sports (Curry, Snyder, Cook, Ruby, \& Rehm, 1997; Snyder, 2004), and a growing number of studies in academic settings indicate positive relationships among hope and academic performance (Curry et al., 1997).

Jackson, Weiss, Lundquist, and Hooper (2003) examined the degree to which hope, procrastination, and social activity predicted academic performance along with composite ACT scores, total credit hours attempted and completed during college, and cumulative GPA. Participants, predominately Caucasian (93\%) and female (64\%) were first year undergraduate students who were enrolled in psychology classes at a Midwestern university. In the fourth week of the first semester, participants completed measures of trait procrastination, trait hope, and social activity. At the end of the academic year, academic performance data were collected.

Jackson and his associates (2003) found that ACT scores, hope, procrastination, and social activity had significant bivariate correlations with GPA. A hierarchical multiple regression analysis also indicated that the most significant individual predictor in this study was ACT scores; higher ACT scores prior to admission predicted high cumulative GPA in college. This finding, however, is limited and may not be generalizable to community colleges and developmental students, especially because passing scores on SAT/ACT are not precursors to admission due to open-admission policies. Some community college systems opt to use student results for placement from other measures, such as the College Placement Test. While dispositional hope was not significant in predicting GPA, Jackson and his associates recognize the limits of their study given that most respondents were in their first year of study with a mean age of 
19.95 years. This suggests that the majority of these students were White, direct-entry enrollment from high school, requiring little or no developmental education coursework.

The results for a positive association between hope and academic success are mixed. It is too early to exclude hope as an important factor particularly for developmental, diverse, community college students, and more research is needed.

Hope and Persistence

Only a few studies have examined the predictive value of hope on persistence in the college setting. Snyder et al. (2002) found higher graduation rates and lower dropout rates over a 6-year period among college students with higher hope scores. In their study, Snyder and his colleagues purposed to expand beyond cross-sectional studies and relate hope to academic outcomes as measured by grade point average, previous ACT scores, and persistence to graduation. A cluster sample of 213 newly admitted college freshman students was drawn from 808 students who were enrolled in an introductory psychology course at a Midwestern state university and completed Snyder's Hope Scale. The sample was then divided into three groups based on students' levels of hope: high-hope, mediumhope, and low-hope. A week after the beginning of the term, these freshmen completed the Hope scale, responding to 12 items designed to assess agency and pathways thinking. The sample group also participated in focus groups of 20 .

The mean composite ACT score was 22.88 and after 6 years, the mean GPA was 2.67. As for enrollment status, 29 students $(13.6 \%)$ were dismissed for poor grades, 58 (27.2\%) withdrew in good academic standing, 24 (11.3\%) persisted and were still enrolled, and 102 persisted to graduation (47.9\%). Using a one-way ANOVA, Snyder and his colleagues (2002) found significance between dispositional hope (three levels) and 
grade point average. Students with higher hope scales had higher grade point averages after controlling for ACT scores, and these relationships were established at the completion of the first semester. Using a two-way contingency table, Snyder and his colleagues also found that students with higher hope scores were more likely to persist to graduation than those with lower hope scores. Based on their findings, Snyder and his colleagues recommend additional research in areas where academically at-risk students are entering college.

Savage and Smith (2007) examined the predictive role of hope as an overall component of goal orientation on degree completion. The setting study was the Community College of the Air Force, and participants were 443 master sergeants enrolled in associate of applied science degrees offered by the College, a non-traditional, non-transfer, regionally accredited community college. The participants completed two measures in the form of an electronic survey that were operationally defined as overall goal orientation: (a) Snyder's Dispositional Hope Scale and (b) a question assessing the desire to complete the degree. Other measures for this study included gender, race/ethnicity, deployment frequency, Armed Services Vocational Aptitude Battery test scores, shift worked, and perceived supervisor support. Using logistic regression analysis, Savage and Smith found that the hope component of the overall goal orientation was a significant predictor of degree completion. The results of the logistic regression analysis showed hope had an odds ratio of 1.05 , and this was significant at $p<.05(p=.01)$.

Both studies (Savage \& Smith, 2007; Snyder et al., 2002) focused on populations that are incongruent with the current study. For example, Savage and Smith (2007) confirmed that their sample was drawn from a specialized community college population, 
which happens to be predominately White, male, and considerably older (mean age $=$ 39.7 years) when compared to the typical community college. Both studies, however, are indications of trends that contribute to our understanding of the influence of noncognitive factors, particularly hope, on academic performance.

Hope and Self-Efficacy as Co-Factors in Influencing Academic Outcomes As discussed throughout this review, the effect(s) of non-cognitive factors on academic outcomes is a subject of continuing practical and empirical interest for higher education practitioners and policy-makers. Exploring the interrelationship of these factors adds to the literature that examines not only the predictive value of these factors but also the unique explanatory power of each factor to influence academic outcomes, particularly persistence, when statistically controlling for cognitive factors such as GPA, prior academic achievement, and standardized test scores. Some studies have included both self-efficacy and hope factors but only to examine the effects of a treatment such as a course or a workshop on the levels of hope and self-efficacy as reported by participants (Ball, 2007; Schemmel, 1999). Only a few studies, however, have investigated selfefficacy and hope in collaboration with other motivational constructs to determine their individual and interacting influence on academic outcomes (Lackaye, Margalit, Ziv, \& Ziman, 2006; Pintrich \& Schunk, 2002), and even fewer have investigated these constructs in a higher education setting. Fewer still have looked at these with community college or developmental students.

In their study, Nietfeld and Enders (2003) explored the interrelationship between two widely studied belief constructs, self-efficacy and goal-orientations, and two emerging constructs, hope and beliefs about knowledge in a higher education setting. 
According to Neitfeld and Enders, other studies have investigated the relationships between a number of these constructs but not in a manner that examined the interaction and predictive value of all four constructs in relation to general ability. The participants in their study were 61 early childhood education teachers, mostly female (95\%) and White (82\%), enrolled in a moderate-sized regional university in the Southeast. Although the exact timing (e.g., at what point during the semester or trimester) of the data collection is not provided, students completed measures for teacher self-efficacy, epistemic beliefs, goals, and hope with no time limit. Afterwards, students performed and completed a 36-item problem-solving task that focused on students' skills in drawing inferences.

Nietfeld and Enders (2003) analyzed their data using descriptive statistics, correlation, canonical correlation, and regression. Descriptive statistics indicated a high degree of hope among the student teachers based on the agency $(M=3.50)$ and pathways $(M=3.12)$ subscales. General teaching efficacy was correlated with the results on the problem-solving task, but no correlation was indicated with the hope scales. After analyzing a series of six canonical correlations among the four constructs, Neitfeld and Enders found non-significant relationships between hope and self-efficacy and significant multivariate relationships among some of the other pairs of variables such as hope and epistemic beliefs and hope and goal orientations. Multiple regression analysis to determine the predictive value of these beliefs on general ability as measured by the problem-solving task was not significant.

While Nietfeld and Enders (2003) did not find significant relationships between hope and self-efficacy, they recognized the importance of follow-up research to examine 
the interrelationship of these belief constructs in various learning environments and on various outcomes such as persistence with struggling students. Nietfeld and Enders (2003) examined the interrelationship between two variables (as opposed to four) within the context of developmental education students. The research sample in this study described in chapter 4 differed in a number of ways as it relates to race and ethnicity, gender, and academic preparedness that did not contribute to the similar results, especially when analyzing the predictive value of self-efficacy and hope on persistence in a developmental writing course. Moreover, this research study differs from Neitfeld and Enders in its focus on human functioning. This study focused on human functioning in a more authentic, real-life setting; that is, students will complete multiple tasks to fulfill course requirements. Nietfeld and Enders (2003) tested the predictive value of belief constructs on general ability as measured by a multiple choice test of abstract reasoning, Raven's Matrices, which has cultural bias implications for non-White, non-Western students (Nell, 2000).

Focused on non-cognitive factors that affect more challenging academic performance (i.e., the completion of a collection of tasks that factor into an end-of-term GPA), Holder (2007) studied the extent to which hope, academics, motivation, and the environment predict persistence in online learning programs. Of all the studies reviewed for this research endeavor, Holder's study is most similar in scope to the current study with some key distinctions in terms of the methodology and participants.

In Holder's (2007) study, participants were 259 students enrolled in associate's, bachelor's, and master's level online programs at a university that is based in the Midwest. The majority of the participants were female, 30-39 years old, White, pursuing 
a bachelor's degree, employed full-time, enrolled full-time, and first-time online learners. This current study only examined those students enrolled in developmental education programs via a developmental education course at a 2-year college. As discussed in Chapter 4, student demographics were markedly different from those reported in Holder's study.

At the midpoint of the first course in a given program, participants in Holder's study (2007) were asked to complete a customized, 60-item survey online that included items from Snyder's Hope scale, Pintrich and McKeachie's Motivated Strategies for Learning Questionnaire, the Grasha-Riechmann Student Learning Styles Scales, and the Learning Orientation Questionnaire. In this study, participants were asked to complete only those measures for hope and self-efficacy, but during the first 3 weeks of a 16-week developmental writing course rather than after substantial experience with success or failure in the course at mid semester. Based on criteria for selecting pre-established instruments (Lodico, Spaulding, \& Voegtle, 2006), the researcher for this study considered the utility and appropriateness of the selected measures for this population. Students who are enrolled in developmental writing courses may also be co-enrolled in developmental reading courses. In other words, students with varying levels of reading skills because of poor academic preparation and/or second language acquisition issues may be co-enrolled in a developmental writing course.

Hoder (2007) used several statistical treatments to analyze responses on the survey. To predict persistence, Hoder used a discriminant function analysis, classifying participants as either persisters or non-persisters. The extent to which all of the assumptions were met for this particular method, however, is not known. Nevertheless, 
Hoder found that participants with high scores in self-efficacy were more likely to persist in online programs. In the current study, the researcher employed research methodology akin to Nietfeld and Enders (2006) - descriptive statistics and regression techniques, which, based on a review of the literature, have been the prevailing treatments when exploring interrelationships and the predictive values of non-cognitive factors.

Summary

Researchers have demonstrated that previous academic performance is a good predicator of achievement in various academic settings, but it is not the only predictor that should be considered or isolated in understanding academic achievement and other academic outcomes in higher education. Based on findings in accumulating research and established theory, motivational factors are also predictive of behaviors related to academic outcomes such as persistence, and at least 109 studies have confirmed the incremental contributions of psychosocial and study skills factors in predicting college outcomes (Robbins, Lauver, Le, Langley, Davis, \& Carlstrom, 2004).

One of the strongest non-cognitive constructs in predicting academic outcomes is self-efficacy (Bandura 1977, 1993; Pajares, 2003), and an extensive body of research has shown that academic self-efficacy is positively associated with persistence (Lent et al., 1984, 1986, 1987). Multon and her colleagues (1991) also confirmed a positive relationship between persistence and self-efficacy in a meta-analysis based on selfefficacy studies executed from 1977 to 1988. Findings from this meta-analysis also suggest that additional research on persistence in more challenging academic contexts is needed. Yet, there is little research that examines academically underprepared students. 
Research on hope in predicting academic outcomes is relatively new in comparison to self-efficacy research, yet the construct has been positively correlated in a number of studies related to health and sports (Curry, Snyder, Cook, Ruby, \& Rehm, 1997; Snyder, 2004). A growing number of studies in academic settings, however, show positive relationships among hope and academic performance (Curry et al., 1997), but only a few studies have examined the predictive value of hope on persistence (Snyder et al., 2002), and these too have generally ignored at-risk students.

Exploring the interrelationship of self-efficacy and hope adds to the literature that examines not only the predictive value of these factors but also the unique explanatory power of each factor to influence academic outcomes, particularly persistence. Some studies have included both factors but only to examine the effects of a treatment such as a course or a workshop on the levels of hope and self-efficacy as reported by participants (Ball, 2007; Schemmel, 1999). Only a few studies, however, have investigated selfefficacy and hope in collaboration with other motivational constructs to determine their individual and interacting influence on academic outcomes (Lackaye, Margalit, Ziv, \& Ziman, 2006; Pintrich \& Schunk, 2002), and even fewer have investigated these constructs in a higher education setting.

Moreover, this kind of research is important in understanding the success of students who enroll in developmental education programs, especially when many students are unsuccessful in or do not complete these programs (Adelman, 2006). The role that hope and self-efficacy play in predicting these outcomes in terms of course completion in the critical first year of college has not yet been investigated. 


\section{CHAPTER III}

\section{RESEARCH DESIGN AND METHODOLOGY}

The following chapter details the methods that were implemented to address the research questions for this study. The first section includes an overview of the problem and purpose, and a restatement of the research questions follows. In the next section, the sample design and demographics are discussed and followed by the research design and data collection protocol, which is consistent with related studies based on a review of the literature. A description of the instrumentation follows with additional discussion concerning selected measures to address the research questions. In the last section, information on statistics used to analyze data is provided.

\section{Purpose}

Researchers have indicated that self-efficacy influences academic motivation to persist (Schunk \& Pajares, 2002). Researchers also indicate self-efficacy beliefs are correlated with motivational constructs and with students' academic performance and achievement (Pajares, 2003). Hope, however, is an emerging psychological construct in the study of factors that influence college outcomes and warrants further exploration within the context of the student departure decision and academic performance, yet little research has been conducted with developmental community college students. The purpose of this study was to determine the relationship among self-efficacy, hope, and persistence of community college students who were enrolled in a developmental education writing course. Specifically, this study was designed to predict, using motivational constructs, academic self-efficacy and hope, students who persist in 
developmental writing courses while controlling for other factors known to be associated with persistence.

\section{Research Questions}

Using a predictive correlational design, the study addressed the following questions:

1. Are hope and self-efficacy distinct for students enrolled in a developmental writing course?

2. After controlling (if significant) for more traditional, research-supported factors that influence student retention at the community college, to what extent do selfefficacy and hope predict course completion in a developmental education course during the first year of college?

3. Does hope account for a significant amount of unique variance independent of self-efficacy?

4. What is the interaction of self-efficacy and hope in predicting completion of a developmental writing course during the first year of college?

\section{Research Population}

The research population was students enrolled in developmental writing coursework at an urban community college. Developmental writing courses may be taught in a variety of formats to include accelerated courses, traditional 16-week courses, online, and hybrid courses. This research population was enrolled in 16-week courses that were delivered in a traditional classroom setting, excluding accelerated, online, or hybrid courses. The groups of interest were students who were enrolled in a developmental writing course and were first-year-in-college. For this research population, the majority of these students were Hispanic, male, and seeking an associate of arts degree. 
In 1984, the Florida Legislature adopted Rule 6A-10.0315, Florida Administrative Code (F.A.C.), to address readiness for college assessment, placement, and instruction. At the community college, all students are required to present proof of college readiness before registering for college-level coursework. Evidence of readiness is indicated by requisite scores on the SAT, ACT, or the College Placement Test. If scores indicate a lack of preparedness for college-level coursework, then students are required to enroll in developmental courses to address basic skills. The three levels of developmental writing are (1) ENC0002 - College Prep Writing I, (2) ENC0020 - College Prep Writing II, and (3) ENC0021 - College Prep Writing III. In this study, the researcher focused on two of three developmental writing courses, ENC0020 and ENC0021, which are traditional firstyear courses for students who require developmental education. These courses also represent the largest enrollment in developmental writing and are designed to equip students with the necessary skills to be confident and competent writers of standard written English and be ready for initial college level writing courses.

ENC0002, the lowest level of developmental writing, was not used in the study. The institution is further investigating placement concerns for students enrolled in ENC002, and the institution has determined that ESL for Academic Purposes may best serve some of these students. If this is the case, students enrolled in this level might require translated instrumentation that was unavailable for this study.

\section{Participants and Sample Selection}

Participants in this study were enrolled in developmental writing courses in the Spring 2009 semester. The researcher worked with Institutional Research to identify fulltime faculty members assigned to teach the designated developmental writing courses 
during the spring term. This decision to use full-time faculty was based on growing research that indicates a negative effect on the persistence of community college students who were exposed to part-time teachers at the community college (Burgess \& Samuels, 1999; Jaege \& Eagan, 2009). Via e-mail, full-time, developmental education writing faculty members were invited to participate in this study and were under no obligation to participate.

Three faculty members responded and 16 course sections of developmental writing were used. This cluster sampling drew 238 participants: 195 (81.9\%) were Hispanic; 19 (8\%) were Black, Non-Hispanic; 11 (4.6\%) were White, Non-Hispanic; 6 (2.5\%) were Asian/Pacific Islander, and 7 (2.9\%) self-reported as Other. Akin to the population, most of the participants were male (52\%) and their ages ranged from 18 to 43 years old $(M=21.20)$.

\section{Data Collection}

The researcher was regularly collecting student data and feedback as part of his role as a full-time employee in the Office of Institutional Effectiveness/Research, the site where this study was conducted. The Office, as part of a broader institutional investigation on the influence of non-cognitive variables, was interested in these findings so the researcher used data collected during Spring 2009 to address these institutional interests. Instruments including a demographic questionnaire, the perceived academic self-efficacy scale, and the hope scale (see Appendix B) were used to collect directly from students during a class session and at the beginning of a standard 16-week semester. Upon completion of the course and with the consent of the student (see Appendix C for informed consent statement and Appendix D for Institutional Review Board approval), 
demographic information and end-of-term grades were obtained from the Office of Institutional Research and collected in a manner consistent with established policies and procedures at the participating institution. Some demographic information, such as a student's total annual income, was self-reported by the student as part of the survey process.

The participating institution traditionally allows one and one-half weeks for students to make changes to their course loads to accommodate unexpected changes in work schedules because the majority of these students are employed. Afterwards, the student forfeits $100 \%$ of her or his tuition and is governed by the institution's financial and withdrawal policies, which includes the issuance of a withdrawal grade on the student's transcript. After students made these adjustments, a stable course enrollment and learning environment were established for the purposes of this study.

Participants were given a questionnaire that included two brief surveys: (a) a general self-efficacy scale (10 items) that was modified for academic purposes, the Perceived Academic Self-Efficacy Scale (Hudson, 2007; Schwarzer \& Jerusalem, 1995) that measures student's beliefs about how she or he can cope with different academic tasks in order to be successful throughout an academic task (Lackeye et al., 2006); and (b) the Adult Hope Scale (12 items) that measures Snyder's cognitive model of hope (Feldman \& Snyder, 2000; Snyder, 1994; Snyder, Harris et al., 1991). Faculty reported that students were able to complete both surveys in less than 15 minutes. At the end of the 16-week course, students' grades, including withdrawal information, were collected for analysis. 


\section{Instrumentation}

A questionnaire and two instruments were used to collect data in order to examine the influence of hope on persistence in developmental writing. These instruments were selected based on previous research in this area and to address this study's research questions.

\section{Perceived Academic Self-Efficacy Scale}

In this study, self-efficacy was measured within the domain of academic functioning in a developmental education writing course. Academic functioning was understood as variations across a number of academic tasks of varying levels and difficulty. In this case of a developmental writing course, this academic functioning was understood accordingly and could be measured across a wide range of challenging situations (Schwarzer, Mueller, \& Greenglass, 1999).

Given the research population and the context (i.e., developmental education) of the academic functioning, the researcher used Hudson's (2007) Perceived Academic SelfEfficacy Scale (PASES), which represents a modified version of Schwarzer and Jerusalem's (1995) General Self-Efficacy Scale (GSES). This scale, along with others, is available in Appendix B. Because perceived self-efficacy is domain specific (Bandura, 1977, 1986), Hudson's modification of Schwarzer and Jerusalem's GSES takes into account academic functioning as opposed to simply general or global self-efficacy. Hudson's scale consists of 10 statements describing the student's beliefs about how she or he can cope with different academic tasks in order to be successful until the completion of the task. Respondents use a 4-point scale to rate their level of confidence, and the sum of responses yields the final composite score with a range from 10 to 40 . 
Hudson appropriates the use of this scale for a population that research commonly identifies as at-risk and prone to academic failure and attrition (Murray, Goldstein, Nourse, \& Edgar, 2000).

Using this scale, Hudson (2007) found a significant relationship $(r=.181, p<.05)$ between self-efficacy and academic performance (i.e., GPA) of college students who were admitted to a university under special admission criteria such as learning disabilities and first generation college student status. Given the open-door policy of the community college, it is likely that similar students reside in the developmental education population. Because the aim is course completion as opposed to more domain-specific tasks, the researcher accordingly opted to use a more global confidence scale that would measure perceived ability based on the challenging situation of being in a developmental education writing course. A Cronbach alpha of .85 was obtained for this measure (Hudson, 2007). For this research sample, a Cronbach alpha of .74 was obtained and is an acceptable reliability estimate (George \& Mallery, 2003).

\section{Hope Scale}

According to Snyder and colleagues (1991), hope is "a positive motivational state that is based on an interactively derived sense of successful (a) agency and (b) pathways thinking" to meet a goal (p. 287). The Adult Dispositional Hope Scale is a 12-item scale that measures Snyder's trait hope along an 8-point continuum (Feldman \& Snyder, 2000; Snyder, 1994; Snyder, Harris et al., 1991; see Appendix B). Agency and pathways items account for eight of the items, four each, and the other four items serve as distracters. The reliability estimates of the instrument have been strong with Cronbach alphas from .74 to .84 and test-retest correlations of .80 or higher at 10 -week and greater intervals. The 
construct validity via principal components exploratory factor analysis (Snyder et al., 1991) and confirmatory factor analysis (Babyak, Snyder, \& Yoshinobu, 1993) corroborated the existence of a two-component (i.e., agency and pathways) model of hope. Roesch and Vaughn (2006) confirmed the factorial validity of the hope scale, suggesting that a two-component model (agency and pathways subscales) better conceptualized than a one-dimensional model of hope. For this research sample, a Cronbach alpha of .75 was obtained and is an acceptable reliability estimate (George \& Mallery, 2003). This also compares with Holder (2007) who obtained a Cronbach alpha of .79 for his investigation of hope along with other factors as a predictor of persistence in online higher education programs.

\section{Measure of Persistence}

While there are many possible ways to measure persistence, for this study, it was measured as course completion. Course completion for this research population, however, included three possible response variables based on assigned grades:

- $\mathrm{S}=$ This grade indicates not only subject matter performance at the "satisfactory" level but also course completion. Students who perform at this level may advance to the next course level.

- $\mathrm{P}=$ This grade indicates that a student is "making progress" in satisfying course competencies. While students who perform at this level may be considered "course completers" or "progressors," they may not advance to the next course level until they have met course competencies.

- $\mathrm{U}=$ This grade indicates subject matter performance at the "unsatisfactory" level. Students who earn this grade are likely to demonstrate no evidence of learning. 
For this study, students who perform at this level are not considered course completers, and they may not advance to the next course level until they have met course competencies.

- $\mathrm{W}=$ This grade indicates that the student withdrew from the course and did not persist.

Although response variables may be collapsed into two categories: completers ("S" \& "P") and non-completers ("U" \& "W"), this action might distort the true picture of course completion, given the studied relationships with regard to the predicated value of self-efficacy and hope on course completion.

\section{Data Analysis Procedures}

The statistical analyses chosen for this study were consistent with previous retention studies that have examined the predictive ability of one or more independent variables on persistence (Gore, 2006; Multon et al., 1991; Robbins et al.2004; Savage \& Smith, 2007). Based on the researcher's review of literature, many of these studies implemented a correlational model that incorporated the use of a number of regression analysis techniques because goals were to infer a predictive relationship between one or more of the criterion variables and persistence as defined in the given study (Gore, 2006; Multon et al., 1991; Robbins et al.2004; Savage \& Smith, 2007). Many of these studies, if not most, have only considered dichotomous response variables (Robbins et al., 2004).

In this study, the response variables included a third category, which Long (1997) suggests may be best investigated using multinomial logistic regression. Multinomial logistic regression still considers the logical relationship between the variables but considers all of the possible categories, even if more than two exist (Long, 1997). If the 
researcher conducted individual logistic regressions, then the researcher would have had a number of possible outcomes whereby a separate regression would have been needed for each possible pair. With multinomial logistic regression these separate calculations for all the possible comparisons were not necessary (Long, 1997). Multinomial logistic regression simultaneously estimates binary logits for all possible comparisons among the outcome categories (Long, 1997). Long (1997) indicates that multinomial logistic regression both "... enforces the logical relationship between the parameters and uses data more efficiently" (p. 151).

In accordance to the steps required to run the multinomial logistic regression, the researcher identified a reference level or a comparison group among the dependent variable categories to which all the other categories were compared. The selection for this study was non-completers of the developmental education course, and this reference group guided the interpretation of the multinomial logistic regression. The comparisons were made against non-completers versus successful completers and non-completers versus non-successful completers. For each comparison, SPSS provided a set of coefficients - an intercept plus coefficients on each variable, and probabilities were predicted for each possible case.

To determine the significance of each model, the final chi-square model statistic was used to provide evidence of the presence of a statistically significant relationship between the dependent variable and the set of independent variables. When there was no overall relationship, Hosmer and Lemeshow (2000) cautions that the researcher should not interpret the independent variable's role in distinguishing between pairs of groups. 
Accordingly, multinomial logistic regressions were conducted to examine all research questions.

Prior to conducting multinomial logistic regressions, descriptive statistics were conducted on all variables to obtain frequencies, percentages, means, and standard deviations to assess the variables within this research study. A description of the variables used in this study is indicated in Table 1.

Table 1

Variable Names and Descriptions

\begin{tabular}{|c|c|}
\hline Variable & Description \\
\hline \multicolumn{2}{|r|}{ Independent } \\
\hline Composite hope score & Scores range from $8-64$ \\
\hline Composite self-efficacy & Scores range from $10-40$ \\
\hline \multicolumn{2}{|r|}{ Dependent } \\
\hline Course persistence & $\begin{array}{l}\text { Coded as } 0=\text { Non-completer, } 1=\text { Successful completer, } \\
\text { and } 2=\text { Non-successful completer }\end{array}$ \\
\hline & Non-Cognitive, Demographic \\
\hline Age & Participant's age \\
\hline Gender & $0=$ Male, $1=$ Female \\
\hline Race/ethnicity & $\begin{array}{l}\text { Coded } 0 \text { to } 5: 0=\text { White non-Hispanic, } 1=\text { Hispanic, } 2= \\
\text { Black non-Hispanic, } 3=\text { Asian/Pacific Islander } 4=\text { Other }\end{array}$ \\
\hline Native language & $\begin{array}{l}\text { Coded } 1 \text { to } 3: 1=\text { Native English speaker, } 2=\text { Native } \\
\text { Spanish speaker, } 3=\text { Other language }\end{array}$ \\
\hline Enrollment status & $\begin{array}{l}\text { Coded } 0 \text { to } 1: 0=\text { First-year college student, } 1=\text { Second- } \\
\text { year college student }\end{array}$ \\
\hline Hours worked per week & Coded 1 to $4: 1=0$ hours and $4=40$ or more hours \\
\hline Total family income & $\begin{array}{l}\text { Coded } 1 \text { to } 5: 1=\text { Less than } \$ 10,400,5=\text { more than } \\
\$ 32,000\end{array}$ \\
\hline Parents' education level & $\begin{array}{l}\text { Coded } 0 \text { to } 4: 0=\text { Did not graduate from HS, } 1=\mathrm{HS} \\
\text { graduate, } 2=\text { Associate's degree, } 3=\text { Bachelor's degree or } \\
\text { higher and } 4=\text { Other }\end{array}$ \\
\hline
\end{tabular}


Afterwards, a series of chi-square tests and an ANOVA were conducted to clarify relationships between demographic, non-cognitive variables, excluding self-efficacy and hope, and the dependent variable (course persistence). The rationale for including these demographic, non-cognitive variables was based on retention studies that confirm significant relationship between some of these variables and persistence in community college (Carter, 2006; Nakajima, 2008). For example, Nakajima (2008) surveyed 427 students at a community college in Southern California to identify and analyze factors that influenced persistence. Among those students who were more likely to persist where those who were younger, those who worked fewer hours, those who enrolled in more hours during a term, and those who did not lack English proficiency. Other factors that influence persistence at the community college include gender, ethnic minority membership other than Asian, and parents' educational background and finances (Bonham \& Luckie, 1993; Gerardi, 1996; Lewallen, 1993). Accordingly, non-cognitive variables were identified as covariates or controls if they significantly related to the dependent variable in this research sample. Later in chapter 4, the researcher reports that these findings were not significant. The researcher recognized the importance of including only significant variables in the multinomial regression models that followed the chi-square procedures, but the researcher included these non-cognitive, demographic variables in a full multinomial regression model to provide the reader with additional data with respect to the variables under consideration. Theoretically, these variables, individually, should account for a significant relationship to the course persistence.

To guard against errors of inference based on multiple multinomial regression runs, the Bonferroni adjustment was considered as a basis for adjusting critical values, as 
required for statistical significance. Agreement in the research community, however, is not consistent (Nakagawa, 2004; Perneger, 1998). For example, some statisticians believe that the Bonferroni adjustment may decrease Type I errors but increase Type II errors (Perneger, 1998). However, the researcher had sound theoretical reasons for selecting the variables in this study (as documented by prior research in Chapter 2) and chose to not do the adjustment. When the research has a sound theoretical basis for multiple comparisons, rather than simply exploratory analyses, all multiple comparison corrections over correct. The Bonferroni adjustment is too conservative in this situation.

\section{Methodological Limitations}

The results of this study may have been affected by grading reliability and differences. Grades are still widely used and acceptable measures of academic performance based on studies that have shown that grades or academic achievement, especially at the post-secondary level, are highly associated with not only academic performance but also persistence at the college level (Pascarella \& Terenzini, 1991, 2005; Zhu, 2002). Furthermore, faculty grading was assumed to be distributed across the range of student hope and self-efficacy as class placement was not based on these factors. Because multiple class sections of developmental writing were used, some degree of grade variability could exist among instructors who evaluated student performance. Consistency, however, was observed in the dissemination of common course competencies for a given course level. All students used the same required textbook for a given course level, and the instructors detailed course expectations (e.g., syllabus) at the beginning of the term. 
The results also have limitations in generalizability. This study was conducted at a community college with a high Hispanic population, so generalizability to other populations should be made accordingly.

With a larger sample, a hold-out group would have been compared with the research sample to determine the stability and replicability of the model. To keep a robust model, this option was not implemented so the study should be replicated.

The results also have limitations in terms of teacher/instructional effect that could not be measured for this study. The researcher assumed that adequate sample randomization allowed this variable to be randomly distributed across the study groups.

Further limitation of the study was the short-term of the outcome measure of persistence. Persistence is often measured over a longer time. Yet, the high association between "gatekeeper" courses and college completion make this a useful early measure.

\section{Summary}

This chapter has detailed the methods that were implemented to examine the influence of hope on persistence in developmental writing. The chapter presented the methods used for each phase of the study, which included a description of the purpose, research questions, research population, data collection, instrumentation, and data analysis procedures. Using a predictive correlational design, the researcher not only included perceived academic self-efficacy as a variable of interest in comparison to hope but also considered additional demographic variables known to impact persistence in community colleges. These variables were not included in the regression models as planned because they were not significant for this research population (see chapter 4 for additional discussion). As part of the analysis procedure, however, it was important to 
show that other possible influences on persistence were considered. This chapter concludes with a description of methodological limitations uncovered in this study. 


\section{CHAPTER IV}

\section{FINDINGS}

The primary purpose of this study was to determine the influence of hope and perceived academic self-efficacy on persistence of students enrolled in developmental writing at an urban community college. Particular attention was paid to the hope construct to determine its unique influence on course persistence. The dependent variable in this study had three categories of course persistence, namely, successful course completion, non-successful course completion, and non-completion.

This chapter contains findings based on statistical treatments of the study variables for the previously stated research questions:

1. Are hope and self-efficacy distinct for students enrolled in a developmental writing course?

2. After controlling (if significant) for more traditional, research-supported factors that influence student retention at the community college, to what extent do selfefficacy and hope predict course completion in a developmental education course during the first year of college?

3. Does hope account for a significant amount of unique variance independent of self-efficacy?

4. What is the interaction of self-efficacy and hope in predicting completion of a developmental writing course during the first year of college?

Descriptive data, including demographic data, means, and standard deviations, for study variables are presented in the first section. Afterwards, results from chi-square 
procedures, ANOVA, and multinomial logistic regression are presented to address each research question.

Descriptive Statistics for Independent, Non-Cognitive, and Dependent Variables A total of 238 students enrolled in a developmental writing course participated in this study. The majority of the participants stated that they were in their first year of college $(n=216,90.8 \%)$ while only a few of them $(n=22,9.2 \%)$ noted that they were in their second year of college (see Table 2).

Table 2

Frequencies and Percentages on Enrollment Status

\begin{tabular}{lcc}
\hline Matriculation & $N$ & $\%$ \\
\hline First year of college & 216 & 90.8 \\
Second year of college & 22 & 9.2 \\
Total & 238 & 100.0 \\
\hline
\end{tabular}

Most of them were men (52.5\%; see Table 3), and, in terms of race and ethnicity, they self-reported as follows: 95 (81.9\%) were Hispanic; 19 (8\%) were Black, NonHispanic; 11 (4.6\%) were White, Non-Hispanic; 6 (2.5\%) were Asian/Pacific Islander and 7 (2.9\%) self-reported as Other (see Table 4). Frequencies and percentages conducted on "native language" revealed that the majority $(n=123,51.7 \%)$ of the participants' native language was English, however, a substantial number of participants also responded with Spanish ( $n=103,43.3 \%$ ) as their native language (see Table 5). 
Table 3

Frequencies and Percentages on Gender

\begin{tabular}{lcc}
\hline Gender & $N$ & $\%$ \\
\hline Male & 125 & 52.5 \\
Female & 113 & 47.5 \\
Total & 238 & 100.0 \\
\hline
\end{tabular}

Table 4

Frequencies and Percentages on Ethnicity/Race

\begin{tabular}{lcc}
\hline Ethnicity/race & $N$ & $\%$ \\
\hline White non-Hispanic & 11 & 4.6 \\
Hispanic & 195 & 81.9 \\
Black non-Hispanic & 19 & 8.0 \\
Asian/Pacific Islander & 6 & 2.5 \\
Other & 7 & 2.9 \\
Total & 238 & 100.0
\end{tabular}


Table 5

Frequencies and Percentages on Native Language

\begin{tabular}{lcc}
\hline Native language & $N$ & $\%$ \\
\hline English & 123 & 51.7 \\
Spanish & 103 & 43.3 \\
Other & 12 & 5.0 \\
Total & 238 & 100.0 \\
\hline
\end{tabular}

Notably, approximately a third $(n=78,32.8 \%)$ of the participants did not work while they were enrolled in college. Fifty-three (22.3\%) worked 1 to 20 hours and 50 (21\%) worked 21 to 34 hours, indicating a relatively even spread of participants for these two categories. The least number of participants $(n=25,10.5 \%)$, however, worked 35-39 hours, and only a few $(n=32,13.4 \%)$ worked 40 or more hours (see Table 6$)$.

Table 6

Frequencies and Percentages on Hours Worked While in College

\begin{tabular}{lcc}
\hline Hours & $N$ & $\%$ \\
\hline 0 & 78 & 32.8 \\
$1-20$ & 53 & 22.3 \\
$21-34$ & 50 & 21.0 \\
$35-39$ & 25 & 10.5 \\
40 or more hours & 32 & 13.4 \\
Total & 238 & 100.0 \\
\hline
\end{tabular}


The results on "total family income" revealed that a little over a third $(n=82$, $34.5 \%$ ) of the participants' family income was greater than $\$ 32,000$. After $\$ 32,000$ the participants most frequently responded $(n=51,21.4 \%)$ that their families earn less than $\$ 10,000$. Almost a fifth of the research sample responded that their incomes were $\$ 10,401-\$ 17,600(n=44,18.5 \%)$, and there were close responses for $\$ 17,601-\$ 24,800(n$ $=32,13.4 \%)$ and $\$ 24,801-\$ 32,000(n=29,12.2 \%$; see Table 7$)$.

Table 7

Frequencies and Percentages on Total Family Income

\begin{tabular}{lcc}
\hline Total family income & $N$ & $\%$ \\
\hline Less than $\$ 10,400$ & 51 & 21.4 \\
$\$ 10,401-\$ 17,600$ & 44 & 18.5 \\
$\$ 17,601-\$ 24,800$ & 32 & 13.4 \\
$\$ 24,801-\$ 32,000$ & 29 & 12.2 \\
More than $\$ 32,000$ & 82 & 34.5 \\
Total & 238 & 100.0 \\
\hline
\end{tabular}

Frequencies and percentages on "either parent's highest education level" revealed that most $(n=104,43.7 \%)$ of the participants responded that their parents had not received a high school diploma while only a few $(n=33,13.9 \%)$ did receive a high school diploma. A substantial number $(n=68,28.6 \%)$ of participants' parents did receive an associate's degree, and some $(n=15,6.3 \%)$ received a bachelor's degree or higher; only a few $(n=18,7.6 \%)$ reported "Other" (see Table 8$)$. 
Table 8

Frequencies and Percentages on Either Parent's Highest Education Level

Either parent's highest education level

No high school diploma

High school diploma

Associate's degree

Bachelor's degree or higher

Other

Total

$N$

104

33

68

15

18

238
$\%$

43.7

28.6

6.3

7.6

100.0

Means and standard deviations were computed on the participants' ages. Results indicated that the average age of the participants was $21.20(S D=3.97)$, with ages ranging from 18 to 43 .

Means and standard deviations were also computed on the hope and perceived academic self-efficacy scores of participants. On the Composite Hope Score, the minimum score was 19 and the maximum score was 64 with a mean of $52.71(S D=$ 6.68). In comparison to other studies of college students referenced in chapter 3 , the mean score is high yet slightly lower than, for example, those reported in Holder's (2007) study. Holder reported a mean hope score of $53.83(S D=5.83)$ that was obtained from students $(N=259)$ enrolled in online program at a Midwestern university.

Student scores on perceived academic self-efficacy ranged from a minimum score of 12 to a maximum score of 40. The average Perceived Academic Self-Efficacy Score was $31.58(S D=4.60)$. In comparison to Hudson's (2007) research study on special 
admissions students at a Southeastern university, this score is only slightly lower than the mean score $(M=33.20, S D=4.60)$ that Hudson obtained for his research sample $(N=$ 117). Statistical means and standard deviations for hope and perceived academic selfefficacy scores are presented in Table 9 as composite scores of the research sample and in categories of course persistence for both constructs.

Table 9

Means and Standard Deviations on Composite Hope and Perceived Academic SelfEfficacy Scores

\begin{tabular}{lllll}
\hline Scores & $N$ Min Max & $M$ & $S D$
\end{tabular}

\section{Hope Score}

Non-completers

Non-successful completers

Successful completers

Total

Self-Efficacy Score

Non-completers

Non-successful completers

Successful completers

Total $\begin{array}{lllll}26 & 19 & 63 & 48.38 & 9.517\end{array}$

$\begin{array}{lllll}19 & 44 & 60 & 52.37 & 5.50\end{array}$

$\begin{array}{lllll}193 & 36 & 64 & 53.33 & 6.13\end{array}$

$\begin{array}{lllll}238 & 19 & 64 & 52.71 & 6.68\end{array}$

Frequencies and percentages were calculated on the dependent variable, course persistence. The majority ( $n=193,81.1 \%)$ of the participants earned the "S" grade, which indicated that they were successful completers of the course. Only a few $(n=26$, 
$10.9 \%$ ), however, earned the "U" or "W" grade, indicating that they were noncompleters. Non-successful completers $(n=19,8.0 \%)$, those who earned "P" grades (meaning they completed the course but did not improve enough to move to the next level) were least represented in course persistence (see Table 10).

Table 10

Frequencies and Percentages on Course Persistence

\begin{tabular}{lcc}
\hline Course persistence categories & $N$ & $\%$ \\
\hline Non-completers & 26 & 10.9 \\
Non-successful completers & 19 & 8.0 \\
Successful completers & 193 & 81.1 \\
Total & 238 & 100.0 \\
\hline
\end{tabular}

Chi-Square Tests for Relationship Between Non-Cognitive and Dependent Variables

To assess for covariates, seven chi-squares were computed to assess if a relationship exists between non-cognitive, categorical variables (native language, enrollment status, gender, race/ethnicity, hours worked while in college, family income, and parents' highest education) by course persistence (non-completers vs..non-successful completers vs. successful completers). The results of the chi-squares are presented in Table 11 and reveal that no significant relationships existed between any of the demographic categorical variables. ${ }^{1}$

\footnotetext{
${ }^{1}$ In spite of this finding, a multinomial regression was conducted with all the non-cognitive, demographic variables with hope and perceived academic self-efficacy, but the model was not significant.
} 
Table 11

Chi-Square Values on Demographic Categorical Variables by Course Persistence

\begin{tabular}{lcc}
\hline Demographic categorical variables & $x^{2}$ & $P$ \\
\hline Native language & 2.82 & .588 \\
Enrollment status & 2.97 & .226 \\
Ethnicity/race & 12.93 & .114 \\
Gender & 2.04 & .360 \\
Hours worked while in college & 5.35 & .719 \\
Family income & 9.01 & .342 \\
Either parent's highest education level & 10.41 & .237 \\
\hline
\end{tabular}

Analysis of Variance for Relationship Between Age and Dependent Variables

A univariate analysis of variance (ANOVA) was conducted on age by course persistence (non-completers vs. non-successful completers vs. successful completers) to assess if any significant mean differences exist between Course Persistence subscales by age. The results of the ANOVA were not significant, $F(2,235)=0.39, p=.678$, suggesting that no significant mean differences existed between age and course persistence. The results of the ANOVA are presented in Table 12.

Table 12

ANOVA on Age by Course Persistence

\begin{tabular}{cccccccccc}
\hline & & & & \multicolumn{2}{c}{ Non-completers } & \multicolumn{2}{c}{$\begin{array}{c}\text { Non-successful } \\
\text { completers }\end{array}$} & \multicolumn{2}{c}{$\begin{array}{c}\text { Successful } \\
\text { completers }\end{array}$} \\
\cline { 5 - 9 } F & Sig. & Eta & Power & $M$ & $S D$ & $M$ & $S D$ & $M$ & $S D$ \\
\hline 0.39 & .678 & 0.00 & 0.11 & 21.70 & 5.12 & 20.65 & 2.89 & 21.19 & 3.90 \\
$(15.87)$ & & & & & & & & & \\
\hline
\end{tabular}

Note. Numbers in parenthesis presents mean squared error. 


\section{Research Question 1}

To examine Research Question 1, a correlation was conducted for hope and perceived academic self-efficacy, and the correlation confirmed a strong relationship between the two variables for this research sample. Hope correlated significantly with self-efficacy $(r=.606, p \leq .01)$. Hope shared about $37 \%$ of its variability with perceived academic self-efficacy $\left(r^{2}=.3672\right)$.

A correlation was also conducted on the two components of hope (pathways and agency) and perceived academic self-efficacy to determine if any one component of hope shared more variability than the other with self-efficacy. The correlation suggested a stronger relationship between the agency component of hope and perceived academic self-efficacy $(r=.585, p \leq .01)$ than the pathways component $(r=.411, p \leq .01)$. Agency and perceived academic self-efficacy shared about $34 \%$ of their variance $\left(r^{2}=.342\right)$ while pathways and perceived academic self-efficacy shared only $17 \%$ of their variance $\left(r^{2}\right.$ $=.168$ ). Fisher's $Z$ transformation was used to confirm this relationship, comparing these correlations. A test statistic and P-value was computed for the pair of correlations testing the hypothesis that the estimate for the agency component of hope and perceived academic self-efficacy indicated a stronger relationship than that of the pathways component of hope and perceived academic self-efficacy. There was a significant difference in these correlations (Fisher's $\mathrm{Z}=2.33, P<0.05$ ).

\section{Research Question 2}

Results from chi-square procedures and ANOVA (see Table 11 and Table 12, respectively) did not confirm any of the non-cognitive variables as covariates or controls. In practice, these variables are significant, so the researcher ran a multinomial logistic 
regression to further complement this finding (see Appendix A). The final model chisquare indicated the presence of a relationship between course persistence and the combination of hope, perceived academic self-efficacy and the demographic variables $\left(x^{2}(44)=71.202, p<0.05\right)$, and the independent variables accounted for (Naglekerke $\left.R^{2}\right)$ $36.6 \%$ of the variance in course persistence. The likelihood ratio test, however, only confirmed a statistically significant relationship between self-efficacy and course persistence $\left(x^{2}(2)=6.481, p<0.05\right)$. Hope and the demographic variables were not significant. Hosmer and Lemeshow (2000) suggest that if the independent variable does not have a significant relationship to the dependent variable, then it has no significance in differentiating between pairs of groups as categorized by the dependent variable.

To further examine Research Question 2, a multinomial logistic regression was conducted to assess if perceived self-efficacy and hope could predict course persistence (non-completers vs. non-successful completers vs. successful completers). The results of the regression were significant $\left(x^{2}(4)=18.76, p<0.001\right)$ and the independent variables accounted for (Naglekerke $R^{2}$ ) $10.7 \%$ of the variance in course persistence.

Overall the regression model correctly predicted $81.9 \%$ of course persistence outcomes. The results of the regression are summarized in Table 13 and suggest that for every one unit increase in perceived self-efficacy, participants were 1.25 times more likely to be categorized as non-successful completers and 1.145 times more likely to be successful completers compared to the reference variable of non-completers. Hope, however, was not significant. 
Table 13

Multinomial Logistic Regression with Self-Efficacy and Hope Predicting Course Persistence

\begin{tabular}{lcccccc}
\hline Variables & B & SE & Wald & df & Sig. & Exp(B) \\
\hline \multicolumn{7}{c}{ Non-successful completers* } \\
Self-efficacy & 0.223 & 0.087 & 6.547 & 1 & 0.011 & 1.25 \\
Hope & -0.011 & 0.056 & 0.041 & 1 & 0.839 & 0.989 \\
\hline & Successful completers* & & & \\
Self-efficacy & 0.135 & 0.064 & 4.529 & 1 & 0.033 & 1.145 \\
Hope & 0.046 & 0.039 & 1.346 & 1 & 0.246 & 1.047 \\
\hline
\end{tabular}

*Comparison group in this model is students who withdrew before the course ended.

\section{Research Question 3}

A multinomial logistic regression was conducted to assess if hope independent of self-efficacy could predict course persistence (non-completers vs. non-successful completers vs. successful completers). The results of the regression were significant $\left(x^{2}(2)=11.34, p<0.01\right)$ and the independent variable of hope accounted for (Naglekerke $\left.R^{2}\right) 6.6 \%$ of the variance in course persistence.

Overall the regression model correctly predicted $81.9 \%$ of course persistence outcomes. The results of the regression are summarized in Table 14. The results suggest that for every one unit increase in hope, participants were 1.103 times more likely to be categorized as successful completers compared to the reference variable of noncompleters. 
Table 14

Multinomial Logistic Regression with Hope Predicting Course Persistence

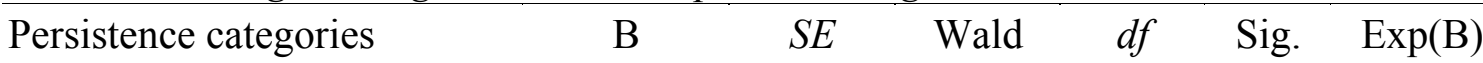

\begin{tabular}{lllllll}
\hline Non-successful completers & 0.074 & 0.044 & 2.774 & 1 & .096 & 1.076
\end{tabular}

$\begin{array}{llllllll}\text { Successful completers } & 0.098 & 0.030 & 10.617 & 1 & .001 & 1.103\end{array}$

As a point of reference and comparison, a multinomial logistic regression was conducted to assess if perceived academic self-efficacy independent of hope predicts course persistence (non-completers vs. non-successful completers vs. successful completers). The results of the regression were significant $\left(x^{2}(2)=16.07, p<0.001\right)$ and the independent variable of perceived self-efficacy accounted for (Naglekerke $R^{2}$ ) $9.2 \%$ of the variance in course persistence.

Overall the regression model correctly predicted $81.5 \%$ of course persistence outcomes. The results of the regression are summarized in Table 15. These results suggest that for every one unit increase in perceived self-efficacy, participants were 1.250 times more likely to be categorized as non-successful completers and 1.197 times more likely to be successful completers compared to the reference variable of non-completers.

Table 15

Multinomial Logistic Regression with Self-Efficacy Predicting Course Persistence

\begin{tabular}{lcccccc}
\hline Persistence categories & B & $S E$ & Wald & $d f$ & Sig. & Exp(B) \\
\hline Non-successful completers & 0.223 & 0.072 & 9.512 & 1 & .002 & 1.250 \\
Successful completers & 0.180 & 0.051 & 12.662 & 1 & .000 & 1.197 \\
& & & & & & \\
\hline
\end{tabular}




\section{Research Question 4}

To examine Research Question 4, a multinomial logistic regression was conducted to assess if the interaction of perceived self-efficacy and hope could predict course persistence (non-completers vs. non-successful completers vs. successful completers). The final model chi-squre supported a relationship between the combination of independent variables (hope, self-efficacy, and the interaction) and course persistence, $\left(x^{2}(6)=19.066, p<0.001\right)$, and this combination accounted for $\left(\right.$ Naglekerke $\left.\mathrm{R}^{2}\right) 10.9 \%$ of the variance in course persistence. Overall, however, as individual variables, these variables were not significant in differentiating between pairs of groups defined by course persistence (see Table 16).

Table 16

Multinomial Logistic Regression with Self-Efficacy, Hope, and the Interaction of SelfEfficacy and Hope Predicting Course Persistence

\begin{tabular}{|c|c|c|c|c|c|c|}
\hline Predictor Variables & B & $\mathrm{SE}$ & Wald & $\mathrm{df}$ & Sig. & $\operatorname{Exp}(B)$ \\
\hline \multicolumn{7}{|c|}{ Non-Successful Completers* } \\
\hline Hope & .013 & .240 & .003 & 1 & .957 & 1.013 \\
\hline Self-efficacy & .278 & .407 & .466 & 1 & .495 & 1.320 \\
\hline Hope X Self-efficacy & -.001 & .008 & .021 & 1 & .884 & .999 \\
\hline \multicolumn{7}{|c|}{ Successful Completers* } \\
\hline Hope & .127 & .170 & .557 & 1 & .456 & 1.136 \\
\hline Self-efficacy & .282 & .306 & .846 & 1 & .358 & 1.325 \\
\hline Hope X Self-efficacy & -.003 & .006 & .245 & 1 & .621 & .997 \\
\hline
\end{tabular}




\section{Summary}

This chapter analyzed this study's research questions based on the methods detailed in chapter 3. Descriptive data, including demographic data, means, and standard deviations, for study variables were presented in the first section. Afterwards, results from chi-square procedures, ANOVA, and multinomial logistic regression were presented to address each research question.

For research question 1, correlational analysis confirmed a significant relationship between hope and perceived academic self-efficacy and a stronger relationship between the agency component of hope and perceived academic self-efficacy than the pathways component. A series of multinomial logistic regression analyses were conducted to assess research questions 2,3 , and 4 .

For research question 2, the researcher intended to include covariates in the regression models and conducted seven chi-squares to determine if a relationship existed between non-cognitive, categorical variables (native language, enrollment status, gender, race/ethnicity, hours worked while in college, family income, and parents' highest education) by course persistence for this research population. The results of the chisquares did not yield significant relationships between any of the demographic categorical variables and the dependent variable. A multinomial logistic regression was conducted to assess if perceived self-efficacy and hope could predict course persistence (non-completers vs. non-successful completers vs. successful completers), but hope was not significant.

For research question 3, a multinomial logistic regression was conducted to assess if hope independent of self-efficacy could predict course persistence (non-completers vs. 
non-successful completers vs. successful completers). The results of the regression were significant and the independent variable of hope accounted for (Naglekerke $\mathrm{R}^{2}$ ) $6.6 \%$ of the variance in course persistence.

For research question 4, a multinomial logistic regression was conducted to assess if the combination of the perceived academic self-efficacy, hope, and the interaction of hope and perceived academic self-efficacy could predict course persistence (noncompleters vs. non-successful completers vs. successful completers). The final model chi-squre supported a relationship between the combination of independent variables (hope, self-efficacy, and the interaction) and course persistence, and this combination accounted for (Naglekerke $R^{2}$ ) $10.9 \%$ of the variance in course persistence. Overall, however, as individual variables, these variables, including the interaction, were not significant in differentiating between pairs of groups defined by course persistence.

Although hope against self-efficacy did not show significant predictive value on course persistence, chapter 5 provides some implications for future research for those who lead and coordinate academic support initiatives in student and academic affairs. 


\section{CHAPTER V \\ DISCUSSION}

In the previous chapter, the researcher analyzed these relationships using correlations and multinomial logistic regression. Prior to these statistical treatments, the researcher also tested additional factors such as age, race/ethnicity, and family income using a chi-square procedure (see Table 12) and ANOVA (see Table 13) to determine if these factors would serve as appropriate covariates because the literature indicates that these factors can influence student retention in the community college setting. They did not influence retention or this research sample drawn from developmental students at a community college.

Accordingly, in this chapter, the researcher provides findings, implications, and conclusions to address some of the issues related to attrition in developmental education programs during students' first year of college. In order to ascertain hope's role in this process, the researcher not only examined hope independently but also in collaboration with self-efficacy, one of the strongest non-cognitive constructs in predicting academic outcomes based on an extensive body of research (Bandura, 1993; Lent et al., 1987; Pajares, 2003).

The following research question questions guided this study:

1. Are hope and self-efficacy distinct for students enrolled in a developmental writing course?

2. After controlling (if significant) for more traditional, research-supported factors that influence student retention at the community college, to what extent do self- 
efficacy and hope predict course completion in a developmental education course during the first year of college?

3. Does hope account for a significant amount of unique variance independent of self-efficacy?

4. What is the interaction of self-efficacy and hope in predicting completion of a developmental writing course during the first year of college?

\section{Discussion of Findings Based on Research Questions}

Initially, the researcher wanted to better understand the relationship between the more widely researched construct, self-efficacy, and the lesser known one, hope. As indicated in the literature review, Neitfeld and Enders (2003) found non-significant relationships between hope and self-efficacy, but this current study confirmed a significant relationship. As a result of the correlational analysis, the researcher confirmed that hope and self-efficacy shared $37 \%$ of their variance but left $63 \%$ of their variance as distinct. Clearly, some overlap existed, but they are distinct concepts.

Theoretically, the two constructs are related, and Bryant and Cvengras (2004) note that hope and self-efficacy have a shared focus on the attainment of specific goals, and this current study supported this relationship. This shared focus is based on a component of hope, identified as agency, which refers to one's capability to persist until goals are attained (Snyder, 2000), and self-efficacy, the belief that one is capable to attain goals (Bandura, 1997). To determine if this theoretical relationship had some statistical support, the researcher tested this relationship between the agency component of hope and perceived academic self-efficacy and confirmed a significant relationship $(r=.585, p$ $\leq .01)$ stronger than that of the pathways component of hope and perceived academic 
self-efficacy $(r=.411, p \leq .01)$. While both components of hope, agency and pathways, were significantly associated with perceived academic self-efficacy, it appears that the greater overlap was with the agency component. This relationship suggests that interventions targeted for this population should focus more on agency rather than pathways. Developmental educators can devise strategies to help students understand the role that motivation and determination plays in achieving personal (and academic) goals. This relationship may be further investigated and used as a framework to better understand persistent behavior in writers who have not mastered competencies in the kind of writing that will support success in college and, ultimately, academic transitions such as exit from developmental education courses or programs, graduation, or transfer to a 4year college.

Given this distinction between these two components of hope, the researcher ran a multinomial logistic regression to determine if hope's components, agency and pathways, independent of each other could predict course persistence. The researcher wanted to confirm whether to better focus the previously established research questions based on this distinction. The results of the regression, however, were not significant, and no additional analysis of these two as separate components ensued. This study's research questions were not altered, but further investigation of agency's possible predictive role in persistence may be needed to explain and understand hope's broader influence and practical implications based on this relationship.

Hope and self-efficacy, though related, are still different constructs, and the key distinction was revealed in the second component of hope, pathways, which refer to one's capability to create routes to goals (Snyder, 2000). That is, hope is not just one's 
capability to persist but also one's capability to create a plan. Perhaps, this distinction also accounted for the portion of hope that did not overlap with perceived academic selfefficacy. What is important about hope is its duality, the interplay of pathways and agency. Snyder (2002) clarifies that

Although pathways and agency thinking are two distinct components of the hope model, they are functionally inseparable. In fact, they are theorized to influence one another reciprocally, such that a change in one will cause a commensurate change in the other. (p. 299)

Not only does this duality link more directly to students' cognition - what students know and do - but it is also consistent with an aim of developmental education, which is to equip students with strategies that they can use to develop skills and dispositions necessary for a successful academic transitions.

Surprisingly, most of the students in this research sample were very hopeful $(M=$ $52.71, S D=6.68)$ and not prone to course attrition. Only $10.9 \%(n=26)$ of the research sample did not persist. This finding is $5.6 \%$ lower than for the developmental student population $(n=151,16.5 \%)$. This finding does not constitute proof that grades are inflated, but the researcher believes that the degree of challenge or difficulty in a developmental writing course, as perceived by developmental students, warrants further investigation. In theory, Lopez, Rose, Robinson, Marques and Pais Reizbero (2009) indicate that students "reporting high levels of hope often prefer stretch goals that are slightly more difficult than previously attained goals" (p. 38). Accordingly, these successful completers may have acquired strategies or at least the motivation to be successful after previous bouts with underpreparedness for college and low achievement. 
Also surprising was the fact that no significant association was established between any of the demographic and non-cognitive variables collected for this study. These variables were identified because they have been widely studied and known to impact retention at the community college. For example, contrary to Nakajima (2008), financial variables (i.e., hours worked while in college and self-reported total family income) were not associated with course persistence in this study. The researcher speculates that the lack of availability of actual financial data as recorded via tax returns used to report this financial data may not have provided a true economic profile of each student, especially when $34.5 \%$ of the sample reported a total family income of more than $\$ 32,000$, which is high in comparison to other campuses system-wide.

As expected, the predictive value of perceived academic self-efficacy independent of hope on course persistence was apparent. The more efficacious students were in their developmental writing courses, the more likely they were to be successful completers (see Table 16), but results for hope independent of perceived academic selfefficacy were not consistent with perceived academic self-efficacy independent of hope. As for the predictive role of hope alone on course persistence, regression results suggest that students who were more hopeful were more likely than less hopeful students to successfully complete their developmental writing courses, but hope did not distinguish between non-successful completers and non-completers. As discussed in Chapter 1, nonsuccessful completers are those students who may have finished the course but not mastered the skills to the level needed to move on to the next course. Accordingly, these students earn progress evaluations as indicated by the "P" grades. Interestingly, descriptive statistics indicated that these students were slightly less hopeful $(M=52.37$, 
$S D=5.5)$ than successful completers $(M=53.33, S D=6.128)$, but a statistically significant relationship was not confirmed. Hence, while the likelihood of these nonsuccessful "progressors" to complete their developmental courses could not be confirmed via regression analysis, the researcher observed an expected trend by categories of completion. Non-completers were less hopeful $(M=48.38, S D=9.52)$ than nonsuccessful completers, and non-successful completers were less hopeful than successful completers. This pattern was unique to hope compared to perceived academic selfefficacy. Non-successful "progressors" were slightly more efficacious $(M=32.74, S D=$ 5.78) than successful completers $(M=31.92, S D=4.22)$.

Certainly, hope alone has some predictive value within the context of course persistence in developmental writing. With hope and perceived academic self-efficacy as cooperating variables, however, findings indicate that hope loses its predictive value (see Table 14). The researcher anticipated that hope would be as powerful in this study as selfefficacy was in the meta-analysis based on 18 self-efficacy studies in Multon et al. (1991). In their study, self-efficacy accounted for $12 \%$ of the students' academic persistence across various types of designs, student samples, and criterion variables. In this study, hope accounted for $6.6 \%$ of the students' course persistence. More studies at 2-year colleges and with developmental education students, however, are needed to strengthen this comparison because only a few studies have examined the predictive value of hope in a college setting.

This finding is also consistent with Holder (2007) who found that hope was not significant as a predictor of persistence in online programs, but self-efficacy was significant. In other words, participants with high scores in self-efficacy were more likely 
to persist in online programs. Holder, however, only considered hope's association between persisters and non-persisters, and this association was statistically nonsignificant. The current research, however, found a positive correlation between the actual variables of hope and persistence to the degree that, on average, as perceived academic self-efficacy scores increase so do hope scores.

The results on the predictive value of hope on persistence were mixed and warrant further investigation. While this study adds to the literature, it is too early to exclude hope as an important factor based on the findings from this study, especially because this study is one of few conducted using a developmental, racially/ethnically diverse and community college research population.

\section{Implications for Additional Research}

Without question, additional research is needed in this area. Although hope against self-efficacy did not show significant predictive value on course persistence, a few implications for future research can be drawn from this study with respect to hope. An initial observation was that a statistically significant majority of the research sample successfully completed developmental writing coursework. This study should be replicated in developmental math and reading courses to determine if hope scores vary across subject-matter. Perhaps students are less hopeful in perceivably and stereotypically more challenging subjects. Because the emphasis is on success in the first year, a more generalized hope might be ascertained by investigating the role that students' hopeful thinking plays in completing the first or the second academic term (of the first year), which would include one or more developmental education courses. 
Surprisingly, this majority also scored relatively high in hope in spite of the potential stigma or labeling associated with taking developmental coursework at the community college. Additional evidence, however, is needed to confirm the hope levels prior to the decision to enroll. These students apparently were ready to confront the challenge of developmental writing coursework, but what other factors may have impacted hopeful thinking at this point in their lives? Could it be that even the decision to attend college in spite of prior academic failures or the decision to return to college after a 3-year hiatus serves as a catalyst for influencing hopeful thinking, or only the optimist would do it? Shorey and his colleagues (2002) posit that high-hope people themselves are sources of hope, but the degree to which high-hope students in this study perceive themselves as sources of hope is unknown. Additional research in this area is recommended, especially research that will elicit an understanding about sources of hope as imbedded in the experience of students.

An example of where sources of hope might be further analyzed is in those students who were less hopeful and, in turn, did not persist. As indicated earlier in Chapter 5, non-completers were less hopeful $(M=48.38, S D=9.52)$ than non-successful completers, and non-successful completers were less hopeful than successful completers. Snyder, Scott, and Cheavens (1999) indicate that in the hope model, "stress, negative emotions, and difficulties in coping are considered a result of being unable to envision a pathway or make movement toward a desired goal" (p. 181). Evidence of these sources might inform the design of interventions to address a student's lack of movement towards a desired goal. 
From a theoretical perspective, Snyder's (2000) hope model assumes that students are goal-oriented as implicated in both definitions of the agency and pathways components of hope (see "Definition of Key Terms" in chapter 1). For this study's research sample, however, this assumption may warrant additional investigation because the researcher could not assume priority placement of goals, whether personal or collegerelated, for the research sample - students who enrolled in developmental writing coursework at a community college. Plausibly, the level of goal orientation, or even the absence thereof, may influence hopeful thinking or, more specifically, agentic or pathways thinking exclusive of each other. For example, a student may not have as her or his goal optimal performance in the developmental writing course because a number of factors beyond cognitive variables (e.g., low college-level placement scores) may have influenced her or his desire to enroll, and these students could be reacting to environmental influences (e.g., parental enforcement) beyond the control of the institution. Again, this reaction may or may not influence levels of hopeful thinking. So additional measures of goal orientation might complement measure of hopeful and efficacious thinking to the extent that a more comprehensive assessment of how goal orientations and motivational constructs such as hope and self-efficacy interact to influence persistence. In other words, students should respond to "I want" statements as well as "I can" and "I believe" statements that are embedded in the hope and self-efficacy measures to determine if correlation and interaction exist.

Multinomial regression confirmed the dynamic relationship that hope and perceived academic self-efficacy share as interacting variables. This interaction may be of practical importance as non-cognitive variables continue to receive additional attention 
in higher education. In fact, the GRE Board and the Educational Testing Service (ETS) have now agreed to start using the Personal Potential Index as part of the actual general GRE to gauge non-cognitive strengths and weaknesses of prospective graduate students (Jaschik, 2008). However, more immediate applications and investigation of noncognitive variables such as hope and self-efficacy are needed whereby additional research might consider how the interaction of self-efficacy and hope (and other non-cognitive variables) over time influence persistence beginning as early as the first year of college. Retention researchers might also consider how the three-way interaction of self-efficacy, hope, and a cognitive variable such as GPA might influence persistence.

For example, in chapter 1 , the researcher noted that previous academic performance is a good predictor of achievement in various academic settings. This study aimed to include the research sample's prior academic performance (as measured by high school GPA) as a covariate. Institutional data in this area were uneven, and cumulative high school GPAs were available for only $51 \%(n=122)$ of the research sample $(M=$ $2.42, S D=.27)$. If available, the relationship of hope to course persistence, especially for "progressors" and non-completers who reported high-hope, would have been analyzed. Additional research on the interaction between hope and prior academic performance on course persistence would be beneficial, strengthening the interpretation of results in light of a key predictor in course persistence.

As expected, the majority of the research population was Hispanic, which leads to additional questions about the socio-cultural factors that inform how these students conceptualize hope in academic settings and what cues - within and without the institution - serve as sources of hope. Is ethnicity a moderating or mediating variable that 
might further explain the relationship between hope and persistence? A qualitative research approach might also provide a means for further investigating these sociocultural factors as part of the lived and articulated experiences of students with respect to the development of their hopeful thinking. That is, what sources of hope may have informed their lived experience as a completer or non-completer in developmental education coursework? Are there shared or culture beliefs that frame students' understanding of hope and their development of hopeful thinking?

Implications and Recommendations for Practice

Appropriating findings from persistence research is complex, especially in consideration of the various limitations or contexts of any study. As indicated earlier, 2year or community colleges have not been widely studied, so this research, with its limitations, contributes to scholarship on students in developmental education programs at community colleges. In fact, the recent, heightened appeal the community college in times of economic recession serves as a clarion call to address issues of persistence for a college population that will continue to diversify on a number of levels. Findings from this study, then, should be applied conservatively within the framework of lessons learned and in the spirit of promoting more action research and assessment in the areas of academic support for developmental education students in their $1^{\text {st }}$ year of college.

Given the aforementioned disclaimer, there are a few practical recommendations for community colleges with developmental writing programs based upon the results of this study and previous investigations. The following practices are recommended: 1. Community colleges should expand assessment of college readiness to include non-cognitive indicators. Community college educators, whether serving in an advisory 
role or an instructional role, must employ a variety of strategies to help developmental students meet crucial milestones along their college journey. The most immediate milestone for this group is college readiness, and more attention must be given to this readiness as being not only students' attainment of knowledge or a set of skills to be successful in college but also their capacity to cope with the rigors of college life or their ability to set career goals, for example, and meet them. For this to be accomplished in developmental education programs, educators must commit to equipping students not only with a cognitive set of skills, as indicated earlier, but also a non cognitive set that will stimulate habits that will foster high hope.

In terms of the first year of college, this means that community colleges should consider expanding their assessment practices to include more measures of non-cognitive student characteristics such as hope and self-efficacy. Traditionally, colleges collect data to obtain an academic profile of students upon entry to determine skills areas that may need to be addressed in an academic support setting such as a lab or a developmental education course. Findings from this research suggest that colleges consider collecting additional non-cognitive data such as student measures of hope and self-efficacy to complement the aforementioned academic profile. For example, if low hope students are identified at the start of college, then these students may benefit from interventions that promote hope-building and better understanding of how hopeful thinking can contribute to academic success in college. Even this condition invites additional research in the area of testing the effectiveness of academic support interventions on persistence or on increasing hopefulness and efficacy in students enrolled in developmental education programs. 
2. Community colleges should broaden awareness of non-cognitive factors via classroom-based research and professional development opportunities. Presumably, many practitioners are reluctant to give more attention to the non-cognitive in developmental education programs, especially when institutional retention efforts are centered around pass rates and semester-to-semester persistence rates, to name only a few. This study has highlighted the potential contributions of two non-cognitive variables - hope and self-efficacy - in predicting course persistence. Other studies have reported the predictive roles of these two variables as well (see chapter 2). Professional development in the area of action research would allow educators to corroborate these findings and provide new levels of understanding not only about the role of the non-cognitive in the developmental education classroom but also the role of inquiry as a conscious effort to explain classroom-based and, ultimately, programbased patterns of persistence. Even this type of professional development via inquiry may help practitioners reflect on, answer, or raise questions about strategies that impact institutional retention efforts.

3. Community colleges should focus on agency and its role in helping students to establish academic goals. As practitioners (e.g., academic advisors and instructors) become more aware of the role that hopeful and efficacious thinking plays in helping student achieve academic goals, these practitioners become managers of the agency component of hope in some respects. This is one way to help connect students to the institution, which may, in turn, foster goal commitment in at-risk student populations such as the developmental students. As mentioned earlier, hope, for example, is not just thinking about one's capability to persist (known as pathways) but also thinking 
about one's capability to create a plan (known as agency). Moreover, Snyder and his colleagues (2002) suggest that setting goals, alone, will not influence the agency needed to obtain these goals. Hence, practitioners might play an important role in designing interventions that might aid students in action-planning for successful goal attainment (e.g., associate's degree or certificate) and more short term goals like attainment of college-level placement. This approach might mean that more emphasis must be placed on student developmental processes (as opposed to product) that facilitate positive academic outcomes. Certainly, outcomes are important but more intervention at significant milestones in the journey of the student might mean the difference between graduation and dropping-out.

4. Teacher should more often engage in reflection on their individual roles in influencing hopeful and efficacious thinking. Clearly academic support structures can help nurture students' awareness and development of their own hopeful and efficacious thinking, but this action must be carefully integrated into the developmental education curriculum or as part of the in-class teaching and learning experience. If instructors subscribe to examining more non-cognitive factors that might influence better results in their classes, then they might want to explore their own levels of hopeful thought on their expectations of student success in their classes. This dynamic may be carefully understood along with helping students to meet course competencies to maximize learning in developmental education coursework. 


\section{Summary}

The aim of this study was to advance the academic community's awareness of hope as a non-cognitive variable and its influence on college persistence as measured by students' completion of developmental education writing courses. As indicated in the literature review, research on hope in predicting academic outcomes is relatively new in comparison to self-efficacy research, and only a few studies have examined the predictive value of hope on persistence (Savage \& Smith, 2007; Snyder, Shorey, Cheavens, Pulvers, Adams \& Wilklund, 2002). This study, accordingly, contributes to closing the research gap in this area, especially because the aforementioned studies have generally ignored atrisk student populations such as the research population targeted for this study: community college students enrolled in developmental education programs.

Accordingly, this chapter discussed findings based on research questions and prior research. While this study did not reveal a significant relationship between hope compared against perceived academic self-efficacy on course persistence, the influence of hope alone draws attention to additional research in this area. In this chapter, for example, the researcher recommends that more studies at 2-year colleges and with developmental education students are needed to strengthen this comparison between hope and self-efficacy because only a few studies examine the predictive value of hope in a college setting.

Implications and recommendations were also included for those who lead and coordinate academic support initiatives in student and academic affairs, in particular, and in developmental education and retention programs. For example, an important 
recommendation calls for the expansion of institutional practice to include more noncognitive intervention strategies to increase retention developmental writing programs. 


\section{REFERENCES}

Adelman, C. (2006). The toolbox revisited: Paths to degree completion from high school through college. Washington, DC: U.S. Department of Education.

Allen, D. (1999). Desire to finish college: An empirical link between motivation and persistence. Research in Higher Education, 40(4), 461-485.

American College Testing Program. (1998). ACT prediction research service. Iowa City, IA: Author.

Amey, M. J., \& Van Der Linden, K. E. (2002). The institutional context of community college administration. Washington, DC: American Association of Community Colleges.

Astin, A. W. (2000). The civic challenge of educating the underprepared student. In T. Ehrlich (Ed.), Civic responsibility and higher education (pp. 124-146). Phoenix, AZ: Oryx Press.

Astin, A. W. (2004). Why spirituality deserves a central place in liberal education. Liberal Education, 90(2), 34-41.

Bailey, T. R., \& Alfonso, M. (2005). Paths to persistence: An analysis of research on program effectiveness at community colleges. Indianapolis, IN: Lumina Foundation for Education.

Baldwin, J. A., Ebert-May, D., \& Burns, D. J. (1999). The development of a college biology self-efficacy instrument of nonmajors. Science Education, 83(4), 397408.

Ball, K. (2007). The effects of a self-defense course on college women's self-efficacy, hope, and fear (Doctoral dissertation, Wayne State University, 2007). Dissertation Abstracts International, 68, 11.

Bandura, A. (1977). Self-efficacy: Toward a unifying theory of behavioral change. Psychology Review, 84, 191-215.

Bandura, A. (1986). Social foundations of thought and action: A social cognitive theory. Englewood Cliffs, NJ: Prentice- Hall.

Bandura, A. (1993). Perceived self-efficacy in cognitive development and functioning. Educational Psychologist, 28(2), 117-148. 
Bandura, A. (1997). Self-efficacy: The exercise of control. New York: W. H. Freeman.

Bandura, A. (1994/1998). Self-efficacy. In V. S. Ramachaudran (Ed.), Encyclopedia of human behavior (vol. 4, pp. 71-81). New York: Academic Press. (Reprinted in H. Friedman [Ed.], Encyclopedia of mental health. 1998, San Diego: Academic Press).

Bandura, A., \& Schunk, D. H. (1981). Cultivating competence, self-efficacy and intrinsic interest through proximal self- motivation. Journal of Personality and Social Psychology, 41, 586-598.

Bassarear, T. J. (1991). An examination of the influence of attitudes and beliefs on achievement in a college developmental mathematics course. Research and Teaching in Developmental Education, 7(2), 43-56.

Baum, S., Brodigan, D., \& Ma, J. (2007). Trends in college pricing. New York: The College Board.

Bean, J. (1983). The application of a model of turnover in work organizations to the student attrition process. The Review of Higher Education, 6, 129-148.

Bean, J. P., \& Eaton, S. B. (2000). A psychological model of college student retention. In J. M. Braxton (Ed.), Reworking the student departure puzzle (pp. 48-61). Nashville, TN: Vanderbilt University Press.

Bentler, P. M., \& Speckart, G. (1979). An evaluation of models of attitude- behavior relations. Psychological Review, 86, 452-464.

Berger, J. B., \& Lyon, S. C. (2005). Past to present: A historical look at retention. In A. Seidman (Ed.), College student retention: Formula for student success (pp. 1-30). Westport, CT: ACE/Praeger.

Bettinger, E., \& Long, B. (2005). Addressing the needs of underprepared students in higher education: Does college remediation work? Cambridge, MA: National Bureau of Economic Research.

Boldt, R. F. (1986). Generalizations of SAT validity across colleges. New York: The College Board Publications.

Bonham, L. A., \& Luckie, J. I. (1993). Taking a break in schooling: Why community college students stop out. Community College Journal of Research and Practice, $17(3), 257-270$. 
Braxton, J. M. (2000). Reworking the student departure puzzle. In J. M. Braxton (Ed.), Reworking the student departure puzzle (pp. 1-10). Nashville, TN: Vanderbilt University.

Braxton, J. M., Hirschy, A. S., \& McClendon, S. A. (2004). Understanding and reducing college student departure. ASHE-ERIC Higher Education Report, 30(3).

Bryant, F. B., \& Cvengros, J. (2004). Distinguishing hope and optimism: Two sides of a coin, or two separate coins? Journal of Social and Clinical Psychology, 23(2), 273-302.

Cabrera, A. F., Castaneda, M. B., Nora, A., \& Hengstler, D. (1992). The convergence between two theories of college persistence. Journal of Higher Education, 2, 143164.

Cabrera, A. F., Nora, A., \& Castañeda, M. B. (1993). College persistence: Structural equations modeling test of an integrated model of student retention. Journal of Higher Education, 64, 123-139.

Calcagno, J. C., Crosta, P., Bailey, T., \& Jenkins, D. (2006). Stepping stones to a degree: The impact of enrollment pathways and milestones on older community college student outcomes. CCRC Brief, 32, 1-6.

Carter, L. R. (2006). Noncognitive predictors of academic success and persistence for Hispanic American/first year college students at selected community colleges in West Texas. Unpublished doctoral dissertation, Texas Tech University, Lubbock.

Castles, J. (2004). Persistence and the adult learner. Active Learning in Higher Education, 5(2), 166-179.

Choi, N. (2005). Self-efficacy and self-concept as predictors of college students' academic performance. Psychology in Schools, 42(2), 197-205.

Curry, L. A., Snyder, C. R., Cook, D. L., Ruby, B. C., \& Rehm, M. (1997). Role of hope in academic and sport achievement. Journal of Personality and Social Psychology, 73, 1257-1267.

Damashek, R. (1999). Reflections on the future of developmental education, part II. Journal of Developmental Education, 23(2), 18-20, 22.

Durkheim, E. (1897/1951). Suicide (G. Simpson, Trans.). Glencoe, IL: The Free Press.

Feldman, D. B., \& Snyder, C. R. (2000). Hope for the many: An empowering social agenda. In C. R. Snyder (Ed.), Handbook of hope: Theory, measures, and applications (pp. 389-412). San Diego, CA: Academic Press. 
Finney, S. J., \& Schraw, G. (2003). Self-efficacy beliefs in college statistics courses. Contemporary Educational Psychology, 28(2), 161-186.

Fishbein, M., \& Ajzen, I. (1974). Attitudes towards objects as predictors of single and multiple behavioral criteria. Psychological Review, 81, 59-74.

Gable, S. L., \& Haidt, J. (2005). What (and why) is positive psychology? Review of General Psychology, 9, 103-110.

George, D., \& Mallery, P. (2003). SPSS for Windows step by step. Needham Heights, MA: Allyn and Bacon.

Gerardi, S. (1996). Factors which influence community college graduation. New York: City University of New York/NYC Technical College.

Gloria, A. M., Robinson Kurpius, S. E., Hamilton, K. D., \& Willson, M. S. (1999). African American students' persistence at a predominantly White university: Influences of social support, university comfort, and self-beliefs. Journal of College Student Development, 40, 257-268.

Gore, P. A., Jr. (2006). Academic self-efficacy as a predictor of college outcomes: Two incremental validity studies. Journal of Career Assessment, 14(1), 92-115.

Hall, J. M., \& Ponton, M. K. (2005). Mathematics self-efficacy on college freshman. Journal of Developmental Education, 28(3), 26-33.

Hawley, T., \& Harris, T. (2005). Student characteristics related to persistence for firstyear community college students. Journal of College Student Retention, 7(1-2), 117-142.

Higbee, J. L., Arendale, D. R., \& Lundell, D. B. (2005). Using theory and research to improve access and retention in developmental education. New Directions in Community Colleges, 129, 5-15.

Holder, B. (2007). An investigation of hope, academics, environment, and motivation as predictors of persistence in higher education online programs. The Internet and Higher Education, 10, 245-260.

Hudson, W. E., Jr. (2007). The relationship between academic self-efficacy and resilience to grades of students admitted under special criteria (Doctoral dissertation, Florida State University, 2007). Dissertation Abstracts International, 68, 9.

Irving, L. M., Snyder, C. R., \& Crowson, J. J. (1998). Hope and coping with cancer by college women. Journal of Personality, 66, 195-214. 
Jackson, T., Weiss, K. E., Lundquist, J. J., \& Hooper, D. (2003). The impact of hope, procrastination, and social activity on academic performance of MidWestern college students. Education, 124(2), 310-320.

Jaschik, S. (2008, May 22). Non-cognitive qualities join the GRE. Inside Higher Ed. Retrieved on September 30, 2009, from http://www.insidehighered.com/news/2008/05/22/ets

Kahn, J. H., \& Nauta, M. M. (2001). Social-cognitive predictors of college persistence: The importance of proximal assessment. Research in Higher Education, 42, 633652.

Lackaye, T., Margalit, M., Ziv, O., \& Ziman, T. (2006). Comparisons of self-efficacy, mood, effort, and hope between students with learning disabilities and their nonLD-matched peers. Learning Disabilities Research \& Practice, 21, 111-121.

Lent, R. W., Brown, S. D., \& Larkin, K. C. (1984). Relation of self-efficacy expectations to academic achievement and persistence. Journal of Counseling Psychology, 31(3), 356-362.

Lent, R. W., Brown, S. D., \& Larkin, K. C. (1986). Self-efficacy in the prediction of academic performance and perceived career options. Journal of Counseling Psychology, 33(3), 265-269.

Lent, R. W., Brown, S. D., \& Larkin, K. C. (1987). Comparison of three theoretically derived variables in predicting career and academic behavior: Self-efficacy, interest congruence, and consequence thinking. Journal of Counseling Psychology, 34(3), 293-298.

Lewallen, W. C. (1993). Early alert: A report on two pilot projects at Antelope Valley College. Lancaster, CA: Antelope Valley College.

Ley, K., \& Young, D. (1998). Self-regulation behaviors in underprepared (developmental) and regular admission college students. Contemporary Educational Psychology, 23(1), 42-64.

Lodico, M. G., Spaulding, D. T., \& Voegtle, K. H. (2006) Methods in educational research. Hoboken, NJ: John Wiley \& Sons.

Long, J. S. (1997). Regression models for categorical and limited dependent variables. Thousand Oaks, CA: Sage.

Lopez, F. G., Lent, R. W., Brown, S. D., \& Gore, P. A. (1997). Role of social-cognitive expectations in high school students' mathematics-related interest and performance. Journal of Counseling Psychology, 44(1), 44-52. 
Lopez, S. J., Rose, S., Robinson, C., Marques, S., \& Pais Reibero, J. (2009). Measuring and promoting hope in schoolchildren. In R. Gilman, E. S. Huebner, \& M. Furlong (Eds.), Promoting wellness in children and youth: Handbook of positive psychology in the schools (pp. 37-50). Mahwah, NJ: Lawrence Erlbaum.

Lopez, S. J., Snyder, C. R., Mayar-Moe, J. L., Edwards, L. M., Pedrotti, J. T., Janowski, et al. (2004). Strategies for accentuating hope. In P. A. Linley \& S. Joseph (Eds.), Positive psychology in practice (pp. 388-404). Hoboken, NJ: John Wiley \& Sons.

Magaletta, P. R., \& Oliver J. M. (1999). The hope construct, will, and ways: Their relations with self-efficacy, optimism, and general well-being. Journal of Clinical Psychology, 55, 539-551.

Meier, S., McCarthy, P. R., \& Schmeck, R. R. (1984). Validity of self-efficacy as a predictor of writing performance. Cognitive Therapy and Research, 8, 107-120.

Mouw, J. T., \& Khanna, R. K. (1993). Prediction of academic success: A review of the literature and some recommendations. College Student Journal, 27(3), 328-336.

Multon, K., Brown, S., \& Lent, R. (1991). Relation of self-efficacy beliefs to academic outcomes: A meta-analytic investigation. Journal of Counseling Psychology, $38(1), 30-38$.

Nakagawa, S. (2004). A farewell to Bonferroni: The problems of low statistical power and publication bias. Behavioral Ecology, 15(6), 1044-1045.

Nakajima, M. A. (2008). What factors influence student persistence in the community college setting? (Doctoral dissertation, University of Southern California, 2008). Dissertation Abstracts International, 69, 9.

National Center for Education Statistics. (2004a). The condition of education 2004, indicator 31: Remedial coursetaking. Washington, DC: U.S. Department of Education.

National Center for Education Statistics. (2004b). The condition of education 2004, indicator 18: Remediation and degree completion. Washington, DC: U.S. Department of Education.

National Commission on Writing for America's Families, Schools and Colleges. (2004).

Writing: A ticket to work or a ticket out. New York: The College Board.

Retrieved December 10, 2008, from

http://www.writingcommission.org/prod_downloads/writingcom/writing-ticketto-work.pdf

Nell, V. (2000). Cross-cultural neuropsychological assessment: Theory and practice. London: Erlbaum. 
Nietfeld, J. L., \& Enders, C. K. (2003). An examination of student teacher beliefs: Interrelationships between hope, self-efficacy, goal orientations, and beliefs about learning. Current Issues in Education, 6(5). Retrieved August 7, 2008, from http://cie.asu.edu/volume6/number5/

Nora, A., Barlow, E., \& Crisp, G. (2005). Student persistence and degree attainment beyond the first year in college: The need for research. In A. Seidman (Ed.), College student retention: Formula for student success. Westport, CT: Praeger.

Pajares, F. (1996). Self-efficacy beliefs in academic settings. Review of Educational Research, 66, 543-578.

Pajares, F. (2003). Self-efficacy beliefs, motivation, and achievement in writing: A review of the literature. Reading \& Writing Quarterly, 19, 139-158.

Pajares, F., \& Miller, M. D. (1994). Role of self-efficacy and self-concept beliefs in mathematical problem solving: A path analysis. Journal of Educational Psychology, 86, 193-203.

Parsard, B., \& Lewis, L. (2003). Remedial education at degree-granting postsecondary institutions in Fall 2000. Washington, DC: National Center for Educational Statistics. Retrieved November 11, 2007, from http://nces.ed.gov/pubs2004/2004010.pdf.

Pascarella, E., \& Terenzini, P. (2005). How college affects students: A third decade of research. San Francisco: Jossey-Bass.

Perneger, T. V. (1998). What's wrong with Bonferroni adjustments. British Medical Journal, 316(7139), 1236-1238.

Peterson, C. (2000). The future of optimism. American Psychologist, 55, 44-55.

Peterson, S. L., \& DelMas, R. C. (1996, April). Effects of career-decision-making selfefficacy on the retention of underprepared adults: A path analytic study of student persistence. Paper presented at the Annual Meeting of the American Educational Research Association, New York.

Peterson, S. J., Gerhardt, M. W., \& Rode, J. C. (2006). Hope, learning goals and task performance. Personality and Individual Differences, 40, 1099-1109.

Pintrich, P. R., \& DeGroot, E. V. (1990). Motivational and self-regulated learning components of classroom academic performance. Journal of Educational Psychology, 82(1), 33-40. 
Pintrich, P. R., \& Schunk, D. H. (1995). Motivation in education: Theory, research and applications. Englewood Cliffs, NJ: Prentice-Hall.

Price, J. (1977). The study of turnover. Ames: Iowa State University Press.

Provasnik, S., \& Planty, M. (2008). Community colleges: Special supplement to The Condition of Education 2008 [NCES 2008-033]. Washington, DC: National Center for Education Statistics, Institute of Education Sciences.

Ray, M., Garavalia, L., \& Murdock, T. (2003). Aptitude, motivation, and self-regulation as predictors of achievement among developmental college students. Research \& Teaching in Developmental Education, 20(1), 5-21.

Richardson, R. C., Jr., Okun, M. A., \& Fisk, E. C. (1983). Literacy in the Open-Access College. San Francisco: Jossey-Bass.

Robbins, S., Lauver, K., Le, H., Langley, R., Davis, D., \& Carlstrom, A. (2004). Do psychosocial and study skill factors predict college outcomes? A meta-analysis. Psychological Bulletin, 130, 261-288.

Roedel, T., Schraw, G., \& Plake, B. S. (1994). Validation of a measure of learning and performance goal orientations. Educational \& Psychological Measurement, 54, 1013-1021.

Roesch, S. C., \& Vaughn, A. A. (2006). Evidence for the factorial validity of the Dispositional Hope Scale: Cross-ethnic and cross-gender measurement equivalence. European Journal of Psychological Assessment, 22, 78-84.

Rushing, B. H. (1996). Effects of study skill and systematic desensitization training on mathematics anxiety, mathematics achievement, mathematics self-efficacy, and cognitive interference among university students enrolled in developmental mathematics. Unpublished doctoral dissertation, University of Southern Mississippi.

Savage, J. S., \& Smith, B. H. (2007). General and specific goal orientations as correlates of adult student degree completion: Lessons from the community college of the air force. Journal of College Student Retention: Research, Theory and Practice Issues, 9(4), 461-485.

Scheier, M. F., \& Carver, C. S. (1987). Dispositional optimism and physical well-being: The influence of generalized expectancies on health. Journal of Personality, 55, 169-210.

Schemmel, T. A. (2001). The role of hope in an adult career decision making workshop (Doctoral dissertation, University of Kansas, 2000). Dissertation Abstracts International, 61(10), 3909A. (UMI No. 9991628) 
Schunk, D. H., \& Pajares, F. (2002). The development of academic self-efficacy. In A. Wigfield \& J. S. Eccles (Eds.), Development of achievement motivation (pp. 1531). San Diego, CA: Academic Press.

Schwarzer, R., \& Jerusalem, M. (1995). Generalized self-efficacy scale. In J. Weinman, S. Wright, \& M. Johnston (Eds.), Measures in health psychology: A user's portfolio. Causal and control beliefs (pp. 35-37). Windsor, UK: NFER-NELSON.

Schwarzer, R., Mueller, J., \& Greenglass, E. (1999). Assessment of perceived general self-efficacy on the Internet: Data collection in cyberspace. Anxiety, Stress, and Coping, 12, 145-161.

Seligman, M. E. P., \& Csikszentmihalyi, M. (2000). Positive psychology: An introduction. American Psychologist, 55, 5-14.

Shell, D., Murphy, C., \& Bruning, R. (1989). Self-efficacy and outcome expectancy mechanisms in reading and writing achievement. Journal of Educational Psychology, 81(1), 91-100.

Shorey, H. S., Snyder, C. R., Rand, K. L., Hockemeyer, J. R., \& Feldman, D. B. (2002). Somewhere over the rainbow: Hope theory weathers its first decade. Psychological Inquiry, 13(4), 322-331.

Snyder, C. R. (1994). The psychology of hope. New York: Free Press.

Snyder, C. R. (2000). Handbook of hope: Theory, measures, and applications. San Diego, CA: Academic Press.

Snyder, C. R. (2004). Hope and the other strengths: Lessons from the Animal Farm. Journal of Social and Clinical Psychology, 23(5), 624-627.

Snyder, C. R., Harris, C., Anderson, J. R., Holleran, S. A., Irving, L. M., Sigmon, S. T., et al. (1991). The will and the ways: Development and validation of an individualdifferences measure of hope. Journal of Personality and Social Psychology, 60, 570-585.

Snyder, C. R., \& Lopez, J. J. (2007). Positive psychology: The scientific and practical explorations of human strengths. Thousand Oaks, CA: Sage.

Snyder, C. R., Rand, K. L., \& Sigmon, D. R. (2002). Hope theory: A member of the positive psychology family. In C. R. Snyder \& S. J. Lopez (Eds.), Handbook of positive psychology (pp. 257-276). New York: Oxford University Press.

Snyder, C. R., Scott, T., \& Cheavens, J. (1999). Hope as a psychotherapeutic foundation of common factors, placebos, and expectancies. In M. Hubble, B. Duncan, \& S. 
Miller (Eds.), The heart and soul of change: What works in therapy (pp. 179200). Washington DC: American Psychological Association.

Snyder, C. R., Shorey, H. S., Cheavens, J., Pulvers, K. M., Adams, V. H., \& Wiklund, C. (2002). Hope and academic success in college. Journal of Educational Psychology, 94, 820-826.

Solberg, V. S., O’Brien P., Villareal R., \& Davis, B. (1993). Self-efficacy and Hispanic college students: Validation of the college self-efficacy instrument. Hispanic Journal of Behavioral Sciences, 15(1), 80-95.

Spady, W. (1970). Dropouts from higher education: An interdisciplinary review and synthesis. Interchange, 1, 64-85.

Staats, S. (1989). Hope: A comparison of two self-report measures for adults. Journal of Personality Assessment, 53, 366-375.

Stone, N. R. (1994). Self-evaluation and self-motivation for college developmental readers. Research and Teaching in Developmental Education, 10, 53-62.

Stratton, C. B. (1998). Transitions in developmental education: Interviews with Hunter Boylan and David Arendale. In J. L. Higbee \& P. L. Dwinell (Eds.), Developmental education: Preparing successful college students (pp. 25-36). Columbia: University of South Carolina, National Resource Center for the FirstYear Experience and Students in Transition.

Tennen, H., Affleck, G., \& Tennen, R. (2002). Clipped feathers: The theory and measurement of hope. Psychological Inquiry, 13(4), 311-317.

Terenzini, P. T. (2006). An interview with Dr. Patrick Terenzini. Student Success, 8-9. Retrieved on Retrieved December 15, 2008, from http://www.studentretention.org/20063/studentsuccess0306.pdf

Terenzini, P. T., \& Reason, R. D. (2005, November). Parsing the first year of college: A conceptual framework for studying college impacts. Paper presented at the meeting of the Association for the Study of Higher Education, Philadelphia, PA.

Tierney, W. (1992). An anthropological analysis of student participation in college. Journal of Higher Education, 63, 603-618.

Tinto, V. (1975). Dropouts from higher education: A theoretical synthesis of recent research. Review of Educational Research, 45, 89-125.

Tinto, V. (1993). Leaving college. Chicago: University of Chicago Press. 
Tinto, V. (2006). Research and practice of student retention: What's next? Journal of College Student Retention, 8(1), 1-19.

Torres, J., \& Solberg, S. (2001). Role of self-efficacy, stress, social integration, and family support in Latino college student persistence and health. Journal of Vocational Behaviour, 59, 53-63.

Townsend, B. K., Donaldson, J., \& Wilson, T. (2004, April). Marginal or monumental? Visibility of community colleges in selective higher education journals. Paper presented at the Conference of the Council for the Study of Community Colleges, Minneapolis, MN.

Tracey, T. J., \& Sedlacek, W. E. (1987). A comparison of white and black student academic success using noncognitive variables: A LISREL analysis. Research in Higher Education, 27(4), 333-348.

U.S. Department of Education. (2006). A test of leadership: Charting the future of U.S. higher education. Washington, DC: Author.

Van Gennep, A. (1960). The rites of passage. Chicago: University of Chicago Press.

Wachholz, P. B., \& Etheridge, C. P. (1996). Writing self-efficacy beliefs of high-and low apprehensive writers. Journal of Developmental Education, 19(3), 16-18, 20, 22 , 24.

Wallis, C. (2005, January 17). The new science of happiness. Time. Retrieved August 8, 2008, from

http://www.authentichappiness.sas.upenn.edu/images/TimeMagazine/TimeHappiness.pdf

White, E. M., \& Thomas, L. L. (1981). Racial minorities and writing skills assessment in the California state university and colleges. College English, 43, 276-283.

Zimmerman, B. (2000). Self-efficacy: An essential motive to learn. Contemporary Educational Psychology, 25(1), 82-91.

Zimmerman, B. J. (1995). Self-efficacy and educational development. In A. Bandura (Ed.), Self-efficacy in changing societies (pp. 202-231). New York: Cambridge University Press.

Zimmerman, B., \& Bandura, A. (1994). Impact of self-regulatory influences on writing course attainment. American Educational Research Journal, 31(4), 845-862. 
APPENDICES 


\section{Appendix A}

Multinomial Logistic Regression with Hope, Self-efficacy, and Demographic Variables Predicting Course Persistence

\begin{tabular}{|c|c|c|c|c|c|c|}
\hline Persistence categories & B & $S E$ & Wald & df & Sig. & $\operatorname{Exp}(\mathrm{B})$ \\
\hline \multicolumn{7}{|c|}{ Non-Successful Completers } \\
\hline Hope & --.052 & .066 & .635 & 1 & .426 & .949 \\
\hline Self-efficacy & .249 & .102 & 5.939 & 1 & .015 & 1.283 \\
\hline Age & -.072 & .100 & .515 & 1 & .473 & .931 \\
\hline Less than $\$ 10,400$ & -2.895 & 1.185 & 5.968 & 1 & .015 & .055 \\
\hline$\$ 10,401-\$ 17,600$ & -1.948 & 1.029 & 3.583 & 1 & .058 & .143 \\
\hline$\$ 17,601-\$ 24,800$ & -3.101 & 1.437 & 4.658 & 1 & .031 & .045 \\
\hline$\$ 24,801-\$ 32,000$ & -.761 & 1.312 & .337 & 1 & .562 & .467 \\
\hline More than $\$ 32,000$ & $0^{\mathrm{b}}$ & & & 0 & & \\
\hline 0 hours worked & 1.828 & 1.288 & 2.015 & 1 & .156 & 6.218 \\
\hline $1-20$ & .987 & 1.313 & .565 & 1 & .452 & 2.683 \\
\hline $21-34$ & 1.098 & 1.362 & .650 & 1 & .420 & 3.000 \\
\hline $35-39$ & -18.088 & 4976.056 & .000 & 1 & .997 & $1.394 \mathrm{E}-8$ \\
\hline 40 or more & $0^{\mathrm{b}}$ & . & . & 0 & . & . \\
\hline English & 18.152 & .781 & 540.510 & 1 & .000 & 7.643E7 \\
\hline Spanish & 19.050 & .000 & . & 1 & . & $1.876 \mathrm{E} 8$ \\
\hline Other & $0^{\mathrm{b}}$ & & & 0 & & \\
\hline White non-Hispanic & -19.094 & 8032.127 & .000 & 1 & .998 & $5.102 \mathrm{E}-9$ \\
\hline Hispanic & .308 & 1.652 & .035 & 1 & .852 & 1.360 \\
\hline Black non-Hispanic & .311 & 1.910 & .027 & 1 & .870 & 1.365 \\
\hline Asian/Pacific Islander & .479 & 12180.302 & .000 & 1 & 1.000 & 1.614 \\
\hline Other & $0^{\mathrm{b}}$ & & & 0 & & \\
\hline No high school diploma & -2.431 & 1.871 & 1.687 & 1 & .194 & .088 \\
\hline High school diploma & -2.310 & 1.511 & 2.337 & 1 & .126 & .099 \\
\hline Associate's degree & -1.899 & 1.930 & .967 & 1 & .325 & .150 \\
\hline Bachelor's degree or higher & -2.944 & 1.517 & 3.765 & 1 & .052 & .053 \\
\hline
\end{tabular}




\begin{tabular}{|c|c|c|c|c|c|c|}
\hline Other & $0^{\mathrm{b}}$ & & & 0 & & \\
\hline Male & -1.268 & .750 & 2.856 & 1 & .091 & .281 \\
\hline Female & $0^{\mathrm{b}}$ & . & . & 0 & . & . \\
\hline \multicolumn{7}{|c|}{ Successful Completers } \\
\hline Hope & .057 & .048 & 1.451 & 1 & .228 & 1.059 \\
\hline Self-efficacy & .123 & .078 & 2.522 & 1 & .112 & 1.131 \\
\hline Age & -.025 & .061 & .173 & 1 & .677 & .975 \\
\hline Less than $\$ 10,400$ & -1.513 & .812 & 3.471 & 1 & .062 & .220 \\
\hline$\$ 10,401-\$ 17,600$ & -2.007 & .810 & 6.135 & 1 & .013 & .134 \\
\hline$\$ 17,601-\$ 24,800$ & -1.368 & .884 & 2.397 & 1 & .122 & .255 \\
\hline$\$ 24,801-\$ 32,000$ & -.227 & 1.018 & .049 & 1 & .824 & .797 \\
\hline More than $\$ 32,000$ & $0^{\mathrm{b}}$ & & & 0 & & \\
\hline 0 hours worked & -1.513 & .812 & 3.471 & 1 & .062 & .220 \\
\hline $1-20$ & -2.007 & .810 & 6.135 & 1 & .013 & .134 \\
\hline $21-34$ & -1.368 & .884 & 2.397 & 1 & .122 & .255 \\
\hline $35-39$ & -.227 & 1.018 & .049 & 1 & .824 & .797 \\
\hline 40 or more & $0^{\mathrm{b}}$ & & & 0 & . & . \\
\hline English & .303 & 1.249 & .059 & 1 & .808 & 1.354 \\
\hline Spanish & .145 & 1.272 & .013 & 1 & .909 & 1.156 \\
\hline Other & $0^{\mathrm{b}}$ & & & 0 & & \\
\hline White non-Hispanic & .111 & 1.403 & .006 & 1 & .937 & 1.117 \\
\hline Hispanic & 1.682 & 1.145 & 2.156 & 1 & .142 & 5.376 \\
\hline Black non-Hispanic & -.004 & 1.334 & .000 & 1 & .998 & .996 \\
\hline Asian/Pacific Islander & 19.896 & 8702.716 & .000 & 1 & .998 & $4.375 \mathrm{E} 8$ \\
\hline Other & $0^{\mathrm{b}}$ & & & 0 & & \\
\hline No high school diploma & -1.207 & 1.376 & .770 & 1 & .380 & .299 \\
\hline High school diploma & -.296 & 1.242 & .057 & 1 & .812 & .744 \\
\hline Associate's degree & .185 & 1.632 & .013 & 1 & .910 & 1.204 \\
\hline
\end{tabular}




$\begin{array}{lcccccr}\text { Bachelor's degree or higher } & -1.475 & 1.246 & 1.400 & 1 & .237 & .229 \\ \text { Other } & 0^{\mathrm{b}} & & & 0 & & \\ \text { Male } & -.996 & .538 & 3.424 & 1 & .064 & .369 \\ \text { Female } & 0^{\mathrm{b}} & & & 0 & & \end{array}$


Appendix B

HOPE AND SELF-EFFICACY SURVEY

Student ID\#

1. Are you seeking a degree or certificate from this college? (mark all that apply)

(a) Yes, an Associate in Arts (A.A.) degree

(5) Yes, an Associate in Science (A.S.) degree

(C) Yes, another degree or certificate (please list)

(16) No, I am not seeking a degree or certificate

() Not sure

2. What are your primary reasons for attending college? (mark all that apply)
(a) Eam a degree or certificate
(4) Upgrade skills
(C) Get a better job
(d) Make more money
() Other, please list

3. How many semesters have you completed so far at this college?
(a) $0-3$
(6) $4-6$
(c) $7-9$
(6) 10 or more

4. How would you describe yourself?
(9) Asian/Pacific Islander/American Indian
(b) Black non-Hispanic
(C) Hispanic
(d) White non-Hispanic
(C) Other

5. What is your gender?
(3) Male
(b) Female

6. What is your age?
(a) Under 18
(b) $18-20$
(c) $21-25$
(4) $26-35$
() Over 35

Birthdate:

7. How many hours per week do you work while attending college?
(a) None
(b) $1-20$
(C) $21-34$
(di) $35-39$
(C) 40 or more

8. What is the total annual income in your home from all sources?
(a) Less than $\$ 10,400$
(b) $\$ 10,400-\$ 17,600$
(C) $\$ 17,601-\$ 24,800$
(di) $\$ 24,801-\$ 32,000$
(e) $\$$ More than $\$ 32,000$

9. How many people live in your household (including yourself)?
(a) 1
(b) $2-3$
(C) $4-5$
(19) $6-7$
(C) 8 or more

10. What is the highest level of education attained by either of your parents?
(3) Did not graduate from high school
(D) High School graduate
(C) Associate degree
(d) Bachelors degree or higher
(C) Other 
Page 1

\section{Adult Dispositional Hope Scale}

Directions: Read each item carefully. Please rate each item by darkening the circle that best describes YOU using the scale below.

$\begin{array}{ccccccc}\text { Definitely } & \begin{array}{c}\text { Mostly } \\ \text { False }\end{array} & \begin{array}{c}\text { Somewhat } \\ \text { False }\end{array} & \begin{array}{c}\text { Slightly } \\ \text { False }\end{array} & \begin{array}{c}\text { Slightly } \\ \text { True }\end{array} & \begin{array}{c}\text { Somewhat } \\ \text { True }\end{array} & \begin{array}{c}\text { Mostly } \\ \text { True }\end{array} \\ \begin{array}{c}\text { Definitely } \\ \text { True }\end{array}\end{array}$

11. I can think of many

(a)

(1)

(c)

(4)

(c)

(1)

(2)

(1)

12. I energetically pursue my

(9)

(1)

(C)

(4)

(c)

(1)

(2)

13. I feel tired most of the time.

(a)

(1)

(c)

(4)

(e)

(1)

(2)

(11)

14. There are lots of ways around any problem.

(a)

(1)

(C)

(4)

()

(1)

(2)

(1)

15. I am easily downed in an

(a)

(b)

(C)

(4)

(6)

(1)

(2)

(11)

16. I can think of many ways to

(9) (6)

(c)

(4)

(๑)

(1)

(2)

(1) get the things in life that
are important to me.

17. I worry about my health.

(9)

(1)

(c)

(4)

(e)

(1)

(2)

(5)

18. Even when others get discouraged, I know I can

(1)

(c)

(d)

(6)

(1)

(2)

(1)

find a way to solve the problem.

19. My past experiences have prepared me well for my future.

\begin{tabular}{|c|c|c|c|c|c|c|c|}
\hline (a) & (6) & (c) & (4) & (๑) & (1) & (2) & (1) \\
\hline (a) & (b) & (c) & (4) & (c) & (1) & (2) & (11) \\
\hline 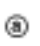 & (1) & (c) & (4) & (๑) & (1) & (2) & (11) \\
\hline (a) & (b) & (C) & (4) & (๑) & (1) & (2) & (19) \\
\hline
\end{tabular}

\section{Perceived Academic Self-Efficacy Scale}

Directions: Read each item carefully. Please rate each item by

darkening the circle that best describes YOU using the scale below.

23. I can always manage to solve difficult academic problems if I try hard enough.

24. If someone opposes me educationally. I can find means and ways to get what I want.

$\begin{array}{cccc}\begin{array}{c}\text { Not at all } \\ \text { true }\end{array} & \begin{array}{c}\text { Barely } \\ \text { True }\end{array} & \begin{array}{c}\text { Moderately } \\ \text { True }\end{array} & \begin{array}{c}\text { Exactly } \\ \text { True }\end{array} \\ \text { (1) } & \text { (1) } & \text { (C) } & \text { (1) } \\ \text { (1) } & \text { (1) } & \text { (C) } & \text { (1) }\end{array}$


Page 1

25. It is easy for me to stick to my aims and accomplish my educational goals.

26. I am confident that I could deal efficiently with unexpected academic events.

27. Thanks to my resourcefulness, I know how to handle unforeseen academic situations.

28. I can solve most school problems if I invest the necessary effort.

29. I can remain calm when facing academic difficulties because I can rely on my coping abilities.

30. When I am confronted with a school problem, I can usually find several solutions.

31. If I am in academic trouble, I can usually think of something to do.

32. No matter what comes my way academically, I'm usually able to handle it.

\begin{tabular}{|c|c|c|}
\hline (a) & (6) & (C) \\
\hline (a) & (6) & (C) \\
\hline (a) & (6) & (C) \\
\hline (a) & (6) & (C) \\
\hline (a) & (6) & (C) \\
\hline (a) & (6) & (C) \\
\hline (a) & (6) & (C) \\
\hline (a) & (b) & (C) \\
\hline
\end{tabular}

33. Do you plan to continue your studies in the fall term?
(a) Yes
(6) No
(C) Uncertain

Please use the space below and explain your answer.

Thank you for

your participation. 


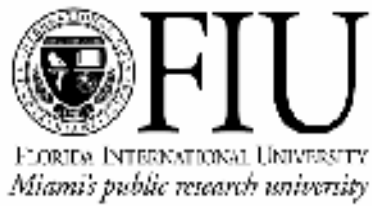

\section{CONSENT TO PARTICIPATE IN A RESEARCH STUDY}

\section{Title: The Interrelationship between Academic Self-Efficacy and Hope on Community College Persistence in a Developmental Writing Course}

You are being asked to participate in a research study. The investigator of this study is S. Sean Madison, a doctoral student at FIU. The study will indude over 200 students enrolled in developmental (aka "college prep") writing courses. Your participation will take about 20 minutes of your time. We are looking at the possible link between students' self-beliefs and hope and the relationship of these two factors to completing a developmental writing course.

If you decide to be a part of the study, you will complete two short surveys in class. On one, you will be asked how confident you are in your ability to accomplish an academic task. On the other, you will be asked to assers your ability to begin and follow-through on actions. These surveys wil be similar to interest, personality and vocational assessments already offered at your institution and used to support student success. Therefore, we do not expect any harm to you by being in the study.

There is no cost or payment to you as a subject. You will not get any direct benefit from being in the study. However, your help will give us information about ways that institutions can improve student achievement in college prep or developmental education courses for those students coming after you.

Your name will not be associated with your survey responses, and all responses will be kept confidential. Your data, including your grades at the end of the term, will be compared to the data of the other students. We will present the research results as a group. You may ask questions about the study at any time. If you choose not to participate, no one will be upset with you. You may also stop your participation before your finish the survey at any time.

If you would like more information about this research after you are done, you can contact Dr. Glenda Musoba or me at 305-348-2450. If you feel that you were mistreated or would like to talk with someone about your rights as a volunteer in this research study you may contact Dr. Patricia Price, the Chairperson of the FIU Institutional Review Board at 305-348-2618 or 305-348-2494.

Your signature below indicates that all questions have been answered to your Iking. You are aware of your rights and you would like to be in the study.

Signature of Participant

Printed Name

Date

I have explained the research procedure, subject rights and answered questions asked by the participant. I have offered himher a copy of this informed consent form. 


\section{Appendix D}

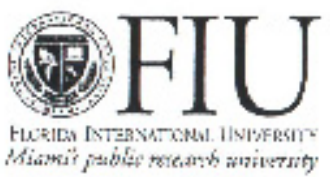

\section{MEMORANDUM}

To:

Stephen Sean Madison

C:

Dr. Glenula Musoba

File

From:

Chris Cirayson, CIM, Assi. Director cf Research Compliance $O f$

Date:

January 9, 200y

Proposal Title: The Interelutionstip Betwecn Academic Sell-Cflicacy and Hope on Community College Persisterce in a Developmental Writing, Ciurse

Approval \# 010609-00

Your study was deemed Excmpt by the Iostilutional Review Board ut Florida International University on January 6, 2009

As a requirement of IIRB approval you are reguirat to.

1) Submit a compleiton report (Form B-2) upun completion of your project in order for the tile to be thised.

2) Submit a proposal and receive approval for any additions er changes in the parcelures involvitig human subjocts.

3) Provide immediale written notification to the $1 R B$ of every sericus or unusual t:r unanticipated adverse event as well as problems with the rights or wel are of the buman subjects. You must confirm the recoipt of serious AE reports with the IRB ollice

Special Conditions: NiA

I'lease note your approval murnoer is indicatec above. For further unformation, yu may contact the IRB Coordinator by email at irbiacueis: hiu.edu or visit toe ORI - Heman Subjects webs:te al htup:iori.fiu.cduilleB.huml. 
VITA

\section{STEPHEN SEAN MADISON}

1993

1994

$1994-1998$

1997

$1998-2003$

$2003-2007$

$2007-2009$
B.A., English Literature and Languages

Morehouse College

Atlanta, GA

M.A., Teaching English

Boston University

Boston, MA

Assistant Professor of English

At an associate degree granting public institution in the Southeastern United States

Instructor and Mentor

Institute for the Recruitment of Teachers at Phillips Academy Andover, MA

Department Chairperson

College Preparatory Studies, English and Reading

At an associate degree granting public institution in the Southeastern United States

Dean, Academic and Student Affairs

At an associate degree granting public institution in the Southeastern United States

Director, Learning Outcomes Assessment Office of Institutional Effectiveness

At an associate degree granting public institution in the Southeastern United States 